\title{
Activation of Epithelial-Mesenchymal Transition and Altered $\beta$-Catenin Signaling in a Novel Indian Colorectal Carcinoma Cell Line
}

\begin{abstract}
Sanghamitra Mylavarapu ${ }^{1,2}$, Harsh Kumar ${ }^{3,4}$, Smita Kumari ${ }^{1}$, L. S. Sravanthi ${ }^{5}$, Misti Jain ${ }^{6}$, Aninda Basu ${ }^{6}$, Manjusha Biswas ${ }^{7}$, Sivaram V. S. Mylavarapu ${ }^{3,4}$, Asmita Das ${ }^{2 *}$ and Monideepa Roy ${ }^{1,5 *}$

${ }^{1}$ Invictus Oncology Pvt. Ltd., New Delhi, India, ${ }^{2}$ Department of Biotechnology, Delhi Technological University, New Delhi, India, ${ }^{3}$ Regional Centre for Biotechnology, Faridabad, India, ${ }^{4}$ School of Life Sciences, Manipal Academy of Higher Education, Manipal, India, ${ }^{5}$ India Innovation Research Center, New Delhi, India, ${ }^{6}$ Division of Cancer Biology, MITRARxDx India Pvt. Ltd., Bangalore, India, ${ }^{7}$ Department of Molecular Pathology, MITRARxDx India Pvt. Ltd., Bangalore, India
\end{abstract}

OPEN ACCESS

Edited by:

Saraswati Sukumar, Johns Hopkins University,

United States

Reviewed by:

Sheetal Parida,

Johns Hopkins University,

United States

Krishan Kumar,

Northwestern University,

United States

*Correspondence:

Monideepa Roy

mroy@invictusoncology.com

Asmita Das

asmita1710@gmail.com

Specialty section:

This article was submitted to Molecular and Cellular Oncology,

a section of the journa

Frontiers in Oncology

Received: 05 September 2018 Accepted: 18 January 2019

Published: 15 February 2019

Citation:

Mylavarapu S, Kumar H, Kumari S, Sravanthi LS, Jain M, Basu A,

Biswas M, Mylavarapu SVS, Das A and Roy M (2019) Activation of Epithelial-Mesenchymal Transition and Altered $\beta$-Catenin Signaling in a Novel Indian Colorectal Carcinoma Cell Line.

Front. Oncol. 9:54.

doi: 10.3389/fonc.2019.00054
Colorectal cancer is the third major cause of cancer-related mortality worldwide. The upward trend in incidence and mortality rates, poor sensitivity to conventional therapies and a dearth of early diagnostic parameters pose a huge challenge in the management of colorectal cancer in India. Due to the high level of genetic diversity present in the Indian population, unraveling the genetic contributions toward pathogenesis is key for understanding the etiology of colorectal cancer and in reversing this trend. We have established a novel cell line, MBC02, from an Indian colorectal cancer patient and have carried out extensive molecular characterization to unravel the pathological alterations in this cell line. In-depth molecular analysis of $\mathrm{MBCO} 2$ revealed suppression of Ecadherin expression, concomitant with overexpression of EMT related molecules, which manifested in the form of highly migratory and invasive cells. Loss of membrane-tethered E-cadherin released $\beta$-catenin from the adherens junction resulting in its cytoplasmic and nuclear accumulation and consequently, upregulation of $c-M y c . ~ M B C 02$ also showed dramatic transcriptional upregulation of $\beta$-catenin. Remarkably, we observed significantly elevated proteasome activity that perhaps co-evolved to compensate for the unnaturally high mRNA level of $\beta$-catenin to regulate the increased protein load. In addition, there was substantial misregulation of other clinically relevant signaling pathways that have clinical relevance in the pathogenesis of colorectal cancer. Our findings pave the way toward understanding the molecular differences that could define pathogenesis in cancers originating in the Indian population.

Keywords: colorectal cancer, signaling, EMT, $\beta$-catenin, mitotic defects

\section{INTRODUCTION}

Colorectal cancer (CRC) ranks as the third most commonly diagnosed disease and a leading cause of cancer-related mortality worldwide. It is further complicated by the fact that about $50 \%$ of CRC patients develop liver metastases during their lifetime (1). Although there has been a significant advancement in the development of treatment regimens, there is no effective therapy in the clinic for advanced CRC presenting with metastasis. 
Recently, shifting trends have emerged in the global incidence of CRC whereby rapidly developing countries present an increase in both CRC related incidence and mortality. In the developed nations however, there is an upward trend in incidence whereas mortality rates are either stabilizing or decreasing over time (1). CRC in India differs from the trends described in the developed nations mainly due to limited healthcare access coupled with poor socioeconomic backgrounds. In the Indian subcontinent, the annual incidence of colon and rectal cancers are 4.4 and 4.1 per 100,000 respectively (2). Additionally, there are reports of younger patients being usually diagnosed at an advanced stage (3). In recent years, understanding the underlying mechanisms that govern pathogenesis and progression of CRC have been the focus of research. However, majority of studies have been conducted on tumors and cell lines derived from Caucasian patients residing in developed countries. Consequently, most therapeutics used in the clinical management of CRC are based on data generated from the Caucasian population that often prove suboptimal for Indian patients. Since Indian population is genetically diverse (4), defining the contribution of genetic factors that lead to disease progression becomes even more critical for the management of Indian CRC patients.

Molecular alterations are the key contributors toward pathogenesis and progression of CRC, characterized by clearly defined stages starting from early adenoma, intermediate adenoma, late adenoma and carcinoma, leading into the final stage of cancer metastasis (5). Although germline mutations play a predominant role in many CRC patients, the vast majority of CRC cases are sporadic with no prior family history (6). Sporadic pre-cancerous polyps or lesions accumulate further genetic and epigenetic aberrations over time resulting in uncontrolled cellular growth, subsequently enabling the cells to acquire invasive and metastatic properties (7). An insight into the molecular events driving these cellular transitions, particularly toward enhanced invasiveness and metastasis, is crucial for the development of novel treatment regimens to combat CRC. One such critical event is the epithelial to mesenchymal transition (EMT), a series of programmed molecular and biochemical changes that result in cells losing their epithelial features while gaining mesenchymal features, such as loss of cell-cell contact, attaining an elongated spindle shaped morphology and increased motility. Complex networks of signaling pathways orchestrate this phenomenon. The inducers of EMT can downregulate E-cadherin while enhancing the $\mathrm{N}$-cadherin and vimentin levels through modulating EMT-related signaling pathways, including Wnt $/ \beta$-catenin, TGF- $\beta$, and EMT transcription factors, namely, zinc finger E-box binding homeobox (Zeb1/2) and Snail (8). This results in pathological changes in the tissue of origin, marked by uncontrolled cellular proliferation that eventually enables them to form secondary metastatic tumors (9). Activation of the EMT program is contextual whereby the incoming signals from the tumor microenvironment drive the molecular changes that ultimately set in motion the transition of cells from epithelial to mesenchymal states $(10,11)$. Among the myriad signaling molecules and pathways that are involved in the EMT program, crosstalk between these signaling pathways contributes toward pathogenesis and progression of CRC (12-14).
One of the key pathways involved in the EMT transition is the evolutionarily conserved $\mathrm{Wnt} / \beta$-catenin signaling pathway that is involved in tissue morphogenesis during embryonic development $(15,16)$. $\beta$-catenin, the central effector in this pathway, participates in numerous cellular processes that are spatio-temporally separated. At cell-cell adherens junctions, $\beta$ catenin binds directly to the membrane anchored E-cadherin to form a catenin-cadherin complex-a critical mechanism that regulates localized cytoskeleton modulation (16-18). This interaction is thought to be a protective mechanism against proteasomal degradation, stabilizing $\beta$-catenin at the adherens junction $(19,20)$. Loss of E-cadherin from the membrane releases free $\beta$-catenin into the cytoplasm that eventually translocates into the nucleus and acts a transcriptional co-activator of pro-growth genes. Suppression of E-cadherin expression has been implicated in progression of cancer and is associated with poor prognosis and poor survival in many malignancies, including CRC (21). In the absence of an incoming Wnt signal, phosphorylation of a cluster of serine, and threonine residues at the N-terminus of $\beta$-catenin primes it for ubiquitination followed by proteasomal degradation, thus maintaining low levels of $\beta$-catenin in the cell. Mutations in these residues prevent phosphorylation resulting in stabilization and accumulation of $\beta$-catenin and subsequent increase in $\beta$-catenin mediated transcriptional activity (22-25). This is a tightly regulated step during normal cellular functionmis-regulation due to pathological transformation may lead to over-activation of pro-growth genes leading to abnormal cellular proliferation, a hallmark of cancer $(26,27)$.

In this article, we describe a novel CRC cell line, $\mathrm{MBC} 02$, derived from a patient of Indian origin that exhibited features of having undergone at least partial EMT. Significant overexpression of Wnt- $\beta$-catenin, TGF $\beta$, and Notch pathways indicated an overall misregulation of clinically relevant signaling pathways that are also implicated in EMT. Transcriptional suppression of E-cadherin along with increased expression of $\mathrm{N}$-cadherin, vimentin and EMT-related transcription factors, Twist and Zeb were corroborated by phenotypic changes such as enhanced migration and invasiveness and reduced response to standard-of-care therapeutics. $\mathrm{MBC} 02$ showed transcriptional upregulation along with cytoplasmic and nuclear accumulation of $\beta$-catenin, indicating activation of the $\mathrm{Wnt} / \beta$ catenin signaling pathway in this cell line. In addition, increased nuclear accumulation of $\beta$-catenin could be linked to elevated levels of Pin1 expression in MBC02. These observations were further correlated with phenotypes that are typical of $\beta$-catenin driven mitotic defects such as supernumerary centrosomes at interphase and multipolar spindles at metaphase, resulting in cytokinetic failure and an enrichment of multinucleate cells that are aneuploid.

\section{MATERIALS AND METHODS}

\section{Immunohistochemical Analysis of Primary Tumor Sections}

Immunohistochemical staining was performed on sections prepared from paraffin-embedded tissue blocks. Sections of 
$\sim 3 \mu \mathrm{m}$ thickness were collected on positively charged slides (TOMO IHC adhesive glass slides, TOM-11). The slides containing the tissue sections were heated at $60^{\circ} \mathrm{C}$ for $1 \mathrm{~h}$, followed by deparaffinization and rehydration by passing through gradient of ethanol solutions and finally placed in deionized water. Heat induced antigen retrieval was performed using citrate based antigen unmasking solution (Vector labs, Cat. No. H3300). Endogenous peroxidase was blocked by incubating the tissue sections in $6 \mathrm{ml}$ of $30 \%$ hydrogen peroxidase solution for $20 \mathrm{~min}$. Ten percent normal goat serum (Vector lab Cat. No. S-1000) was used for blocking non-specific proteins prior to incubation with primary antibody for $1 \mathrm{~h}$, followed by washing with $1 \mathrm{X}$ PBS. The tissue sections were incubated with primary antibodies for $1 \mathrm{~h}$, washed with $1 \mathrm{X}$ PBS and then incubated with HRP labeled secondary antibodies. The sections were again washed with 1X PBS. Freshly prepared chromogenic reagent (antirabbit HRP, Cell Signaling, Cat. No. 8114 s or anti-mouse HRP, Cell Signaling, Cat. No. 8125s) was added to the sections for developing the color to aid visualization of staining. Dako Envision Kit (Cat. No. K5007) was used for Ki-67. All slides were counter-stained with hematoxylin (Merck, Cat. No. 6092530121730), dehydrated by passing through gradient of ethanol solutions, placed in xylene and finally mounted and sealed. Representative images were captured in 200X magnification using Leica’s Aperio ImageScope software (V12.3.3.5048).

\section{Establishment of MBCO2}

Surgically removed tumor tissue was obtained from the primary tumor site of a 37-year-old Indian female CRC patient with disease staging at $\mathrm{T}_{2} \mathrm{~N}_{1} \mathrm{M}_{0}$, after obtaining informed consent under Institutional Review Board (IRB) approved protocol of MITRARxDx India Pvt. Ltd., India (IRB\# TS-04-2011). The tumor tissue was washed extensively with 1X PBS, followed by incubation with $1 \mathrm{X}$ penicillin/ streptomycin for $10 \mathrm{~min}$ at room temperature. The tumor tissue was then sectioned to obtain $0.5-2.0 \mathrm{~mm}^{3}$ size sections. These were then digested with $0.5 \mathrm{X}$ collagenase in DMEM containing $1 \mathrm{X}$ penicillin/streptomycin at $37^{\circ} \mathrm{C}$ for $2-4 \mathrm{~h}$. The disaggregated tumors were passed through a cell strainer and centrifuged to obtain a cell pellet. The cells were then counted by trypan blue exclusion method and seeded in flasks. Unattached cells and tumor debris were removed by changing the media, followed by differential trypsinization to remove fibroblasts. Further inhibition of fibroblast was achieved by growing the cultures in low serum and calcium containing media. The cultures were treated with $0.01 \%$ EDTA for $3 \mathrm{~min}$ and replaced with media containing 5\% FBS for $24 \mathrm{~h}$. Detached fibroblasts were removed by replacing with fresh media. This procedure was repeated for three passages to enrich the cultures for tumor cells. MBC02 cell line was established after sequential passaging and subsequent growth in phenol red free Dulbecco's Modified Eagle Medium (DMEM) containing $5.5 \mathrm{mM}$ glucose supplemented with 10\% FBS and 1X gentamicin. All assays reported in this article were carried out using cells between passages 6 to 20 .

\section{Cell Culture}

MBC02 cells were grown and maintained in phenol red free DMEM-low glucose (HiMedia, Cat. No. AL183A) medium, containing $5.5 \mathrm{mM}$ glucose, $10 \%$ fetal bovine serum (FBS) and supplemented with 1X gentamicin. HCT116, HT29, and SW620 cells were obtained from the American Type Culture Collection (ATCC), grown and maintained in DMEM-high glucose (HiMedia, Cat. No. AL007A) containing $25 \mathrm{mM}$ glucose, supplemented with $10 \% \mathrm{FBS}$ and $1 \mathrm{X}$ penicillin and streptomycin. All cell lines were grown at $37^{\circ} \mathrm{C}, 5 \% \mathrm{CO}_{2}$ atmosphere with relative humidity of $95 \%$. Growth characteristics of MBC02 cells were measured by seeding cells at an initial concentration of 15,000 per well of a 12 well dish and allowed to grow. Cells were trypsinised from a single well and counted at designated time intervals. The population doubling time was calculated using the following formula: $\mathrm{DT}=\mathrm{T} \log 2 / \log \left(\mathrm{X}_{\mathrm{e}} / \mathrm{X}_{\mathrm{b}}\right)$, where, $\mathrm{T}$ is the time period, $\mathrm{X}_{\mathrm{e}}$ is the number of cells at the end of the incubation time and $\mathrm{X}_{\mathrm{b}}$ is the number of cells at the beginning of the incubation time.

\section{Karyotype Analysis}

MBC02 cells from passage number 8 and 16 were cultured in $5 \mathrm{ml}$ of recommended media supplemented with $10 \%$ FBS and incubated in a humidified $\mathrm{CO}_{2}$ incubator at $37^{\circ} \mathrm{C}$. Demecolcine solution (Sigma Aldrich, Cat. No. 7385) was added at a final concentration of $100 \mathrm{ng} / \mathrm{ml}$ and the cells were incubated for various time intervals (overnight, 24 and $48 \mathrm{~h}$ ). Cells were harvested and centrifuged at 1,200-1,500 rpm for $10 \mathrm{~min}$ at room temperature. The cell pellets were resuspended in $8-10 \mathrm{ml}$ of warm hypotonic solution $(0.075 \mathrm{M} \mathrm{KCl})$ and incubated at $37^{\circ} \mathrm{C}$ for $20 \mathrm{~min}$, followed by addition of $500 \mu \mathrm{l}$ of pre-cooled fixative ( $3: 1$ solution of methanol and acetic acid). The cells were gently mixed for uniform fixation. The cells were centrifuged and resuspended in fresh fixative. This process was repeated twice. The resuspended cells were placed in $-20^{\circ} \mathrm{C}$ overnight. Next day, the fixed cells were dropped onto freshly washed glass slides and allowed to air dry. The dried slides were baked at $65^{\circ} \mathrm{C}$ for $8-12 \mathrm{~h}$. The slides were then sequentially rinsed with trypsin solution (6.25 mg of trypsin in $50 \mathrm{ml}$ Gurr buffer), followed by normal saline and deionized water. The washed slides were stained using Giemsa solution $(2.0 \mathrm{ml}$ of Giemsa stain added to $48 \mathrm{ml}$ of Gurr buffer) for 5-6 min and washed with deionized water. Analyses of the stained slides were carried out using Cytovision software (Leica Biosystems).

\section{Mutational Analysis}

Genomic DNA was extracted from tumor tissues and MBC02 cell line using a QIAamp DNA Micro Kit (Qiagen) and subjected to PCR using region-specific primers to detect the mutational status of KRAS (codon numbers 12, 13, 61, and 146) and BRAF (codon 600). DNA fragment containing KRAS mutation hotspots were amplified with the intron-based primers (28). Reaction mix contained $2.5 \mathrm{mM} \mathrm{MgCl}_{2}, 0.2 \mathrm{mM}$ dNTPs, $1 \mu \mathrm{M}$ of each primer set, and 0.5 units of PhusionTaq (ThermoFisher Scientific) in a total volume of $50 \mu \mathrm{l}$. SW480 bearing mutation in KRAS and Caco2 harboring wild type KRAS were used as controls for PCR and sequencing reactions. PCR was carried out at $95^{\circ} \mathrm{C}$ for $5 \mathrm{~min}$, 
followed by 25 cycles at $95^{\circ} \mathrm{C}$ for $30 \mathrm{~s} ; 60{ }^{\circ} \mathrm{C}$ for $30 \mathrm{~s}$ and $72{ }^{\circ} \mathrm{C}$ for $30 \mathrm{~s}$ with a final extension for $5 \mathrm{~min}$. PCR products were resolved on $1.5 \%$ agarose gel. The amplicons were excised and purified using a QIAquick gel extraction kit according to manufacturer's protocol (Qiagen) and processed for Sanger sequencing.

\section{Anchorage Independent Growth Assay}

Tumorigenic potential of MBC02 cells was asessed using the anchorage independent growth assay. The base layer of agar $(0.5 \%)$ was prepared by mixing $9 \mathrm{ml}$ of complete media to $1 \mathrm{ml}$ of $5 \%$ agar. The temperature of the solution was maintained at $50^{\circ} \mathrm{C}$ to prevent premature solidification of the agar. $1 \mathrm{ml}$ of the agar mix was added to each well of a 6 well plate and allowed to solidify completely. The cells were washed with $1 \mathrm{X}$ PBS and harvested by trypsinization. The cells were centrifuged and resuspended in $1 \mathrm{X}$ PBS and counted. The cell number was adjusted to $5 \times$ $10^{3}$ cells $/ \mathrm{ml}$ in complete media. The top agar layer $(0.3 \%)$ was prepared by adding $0.6 \mathrm{ml}$ of $5 \%$ agar to $9.4 \mathrm{ml}$ of complete media containing cells. $1 \mathrm{ml}$ of the top agar was layered over the base agar and allowed to solidify completely. $800 \mu \mathrm{l}$ of complete media was layered on top to prevent drying of the agar. The plates were incubated at $37^{\circ} \mathrm{C}, 5 \% \mathrm{CO}_{2}$ atmosphere with relative humidity of $95 \%$ for 2 weeks. Colonies were imaged using Nikon TiE inverted microscope.

\section{Cell Cycle Analysis}

The culture media was removed and cells were washed with $1 \mathrm{X}$ PBS. Cells were harvested by trypsinization and collected by centrifugation at $2,000 \mathrm{rpm}$ for $5 \mathrm{~min}$. The cell pellets were washed twice with PBS and centrifuged at 2,000 rpm. The cells were resuspended in $1 \mathrm{ml}$ PBS to obtain single cell suspension and fixed in ice cold $70 \%$ ethanol for at least $4 \mathrm{~h}$ at $4^{\circ} \mathrm{C}$. After fixation, the ethanol was removed by centrifugation and the cells were washed twice with $1 \mathrm{X}$ PBS. Staining solution was prepared by adding propidium iodide at a final concentration of $50 \mu \mathrm{g} / \mathrm{ml}$ and RNAse $A$ at a final concentration of $50 \mu \mathrm{g} / \mathrm{ml}$. The samples were incubated at $37^{\circ} \mathrm{C}$ for $20 \mathrm{~min}$ and data acquired by flow cytometry (BD FACS Verse). Three biological replicates were performed to obtain statistically significant data.

\section{Cell Migration and Invasion Assay}

For would healing assay, MBC02 and HCT116 cells were seeded in 6 well plates and allowed to grow to confluency. After generating a wound in the monolayer, the media was removed and the cells were washed to remove detached cells. The cells were fed with fresh media and the wound was allowed to close. The gap between the invasion fronts was measured at regular interval to calculate the rate of wound closure. We used the transwell migration assay to evaluate the migratory and invasive potential of MBC02 in comparison to HCT116, HT29, and SW620. Boyden chambers with $8 \mu$ pores (BD Falcon, Cat. No. 353097) were placed in 24-well cell culture plates. Cells were trypsinized, washed once in DMEM and counted using a hemocytometer. $1 \times$ $10^{4}$ cells were suspended in $200 \mu \mathrm{l}$ of serum free media and added to the upper compartment of the Boyden chamber in each well of a 24 well plate. The lower compartment contained $400 \mu \mathrm{l}$ of complete media with $10 \%$ FBS. After incubation for $24 \mathrm{~h}$ at $37^{\circ} \mathrm{C}$, assays were terminated by scraping the top of the membrane to remove non-migratory cells. The membranes were fixed in $4 \%$ paraformaldehyde, stained with crystal violet and mounted on glass slides. Quantification of cells was carried out by counting at least three microscopic fields using a 10X objective. Matrigel coated Boyden chambers $(100 \mu \mathrm{g} / \mathrm{ml})$ were used for the invasion assay. $5 \times 10^{4}$ cells were suspended in $200 \mu \mathrm{l}$ serum free media and seeded in each well. The lower chamber contained $400 \mu \mathrm{l}$ of complete media with $10 \%$ FBS. After $24 \mathrm{~h}$ at $37^{\circ} \mathrm{C}$, assays were terminated and cells were quantified as described above for the migration assay. The experiments were repeated at least thrice for obtaining data for statistical significance.

\section{Gene Expression Analysis by qRT-PCR}

Total RNA was isolated from cells using RNeasy Mini Kit (Qiagen, Cat. No. 74104). $1 \mu \mathrm{g}$ of total RNA was used for cDNA synthesis using iScript cDNA Synthesis Kit (BioRad, Cat. No. 170-8891). Real time quantitative PCR was performed using SYBR Green reagent (SsoFast Eva Green supermix, BioRad, Cat. No. 1725202AP) in a CFX Connect Real Time PCR system (BioRad). Cycling conditions were optimized at initial denaturation for $5 \mathrm{~min}$ at $95^{\circ} \mathrm{C}$ followed by denaturation for $5 \mathrm{~s}$ at $95^{\circ} \mathrm{C}$ and annealing, extension for $45 \mathrm{~s}$ at $60^{\circ} \mathrm{C}$ for 40 cycles. GAPDH was used as the internal control and all CT values were normalized to either internal control or HCT116. Sequences of the primers are listed in Table S1. Three biological replicates were performed for each experiment.

\section{Antibodies}

Primary antibodies against Ki67 was procured from Dako (Cat. No. IR626, Clone MIB1) and caspase 3C from Cell Signaling Technology (Cat. No. 9661). Primary antibodies against $\beta$-catenin (Cat. No. 8480), phospho- $\beta$-catenin (Cat. No. 9561) were procured from Cell Signaling Technology; Ecadherin (Cat. No. 33-4000), APC (Cat. No. MA1-26185) from Thermo Scientific; $\alpha$-tubulin (DM1A, Cat. No. T9026) and $\beta$ actin (Cat. No. A3853) from Sigma-Aldrich; $\gamma$-tubulin (Cat. No. A302-631A) from Bethyl Labs; Pin1 (Cat. No. SC-46660) from Santa Cruz Biotechnology. Anti-mouse and anti-rabbit Alexa-488 conjugated (Cat. No. A11008, A11001) and antimouse, anti-rabbit Cy3 conjugated (Cat. No. A10521, A10520) secondary antibodies for immunofluorescence were purchased from Molecular Probes, Invitrogen. Horse Radish Peroxidase (HRP) conjugated anti-mouse (Cat. No. 715-035-150) and antirabbit (Cat. No. 711-035-152) secondary antibodies from Jackson Immunoresearch were used for Western Blot analysis.

\section{Immunofluorescence Staining}

Cells were seeded on glass coverslips and allowed to adhere overnight. The media was removed and the cells washed with PBS and fixed in $3.7 \%$ paraformaldehyde at room temperature for 5 min. Permeabilization was achieved using PBS containing $1 \%$ BSA $+0.5 \%$ Triton $\mathrm{X}-100$ for $1-2 \mathrm{~min}$ at room temperature. Blocking was performed using $1 \%$ BSA $+0.05 \%$ Triton X100 in PBS for $30 \mathrm{~min}$ followed by incubation with primary antibody for $1 \mathrm{~h}$. Primary antibodies were used at the following dilutions: $\alpha$-tubulin $-1: 1,000, \gamma$-tubulin $-1: 500, \beta$-catenin - 
1:200, phospho- $\beta$-catenin - 1:200, E-cadherin - 1:200. After washing with PBS, cells were incubated in secondary antibody for $1 \mathrm{~h}$. The cells were washed with PBS and stained with Hoechst 33258 at a dilution of 1:5,000 from a $5 \mathrm{mg} / \mathrm{ml}$ stock solution. The cells were again washed with PBS and mounted in Prolong Gold mounting medium (Invitrogen). The slides were allowed to dry overnight before imaging using a Nikon TiE Eclipse epifluorescence microscope.

\section{Western Blotting}

Cells were lysed in 1X Radioimmunoprecipitation Assay (RIPA) buffer containing protease inhibitor (Roche, Cat. No. 05892970001) and phosphatase inhibitor (sodium orthovanadate, New England Biolabs, Cat. No. P0758S) at appropriate concentrations. Laemmli buffer containing $\beta$ mercaptoethanol was added and the samples were heated at $95^{\circ} \mathrm{C}$ for $10 \mathrm{~min}$. Samples were loaded on a 10 or $12 \%$ denaturing gel and electrophoresis was performed before transferring the resolved proteins onto PVDF membrane (Millipore). Blocking was done in TBST containing either 5\% skimmed milk or 5\% BSA followed by incubation in primary antibody overnight at $4^{\circ} \mathrm{C}$. Membranes were washed with tris-buffered saline containing $0.1 \%$ tween-20 (TBST) and incubated with HRPconjugated secondary antibody for $2 \mathrm{~h}$ at room temperature. Blots were washed extensively with TBST and chromogenic substrate (Luminata Forte, Millipore) was added to develop the chemiluminescent signal. Images were captured in an Image Quant 4000 (GE) gel documentation system. Primary antibodies were used at the following dilutions: $\beta$-catenin - 1:1,000, Pin 1 $1: 1,000, \beta$-Actin - 1:2,000.

\section{Drug Sensitivity Assay}

Cytotoxicity of bortezomib (ChemShuttle, Cat. No. 179324-697) on $\mathrm{MBC} 02$ and HCT116 cells was measured using MTT assay. Cells were seeded in quadruplicate in the recommended media in 96 well plates at a density of 3,000 cells per well and allowed to attach overnight at $37^{\circ} \mathrm{C}, 5 \% \mathrm{CO}_{2}$ and $95 \%$ humidity. The cells were incubated for $48 \mathrm{~h}$ with different concentrations of bortezomib ranging from 0.03 to $50 \mathrm{nM}$. Untreated cells were used as control. Following incubation, $20 \mu \mathrm{l}$ of $5 \mathrm{mg} / \mathrm{ml}$ MTT (HiMedia, Cat. No. RM1131-1G) solution was added to the cells and incubated for another $3 \mathrm{~h}$. The media containing MTT was completely removed and the formazan precipitate was dissolved using $100 \mu \mathrm{l}$ of 1:1 solution of DMSO: methanol. Absorbance was measured at $550 \mathrm{~nm}$ with background correction at $655 \mathrm{~nm}$ using a microplate reader (iMark, BioRad). The results were analyzed using GraphPad PRISM software (GraphPad, San Diego, CA). The $\mathrm{IC}_{50}$ values were calculated and result plotted as the mean \pm SEM of the absorbance for each tested dose from three independent experiments. MBC02 cells were also treated with a combination of drugs that are the standard-of-care regimen for treatment of $\mathrm{CRC}$. The therapeutic regimens included 5-fluorouracil (5-FU) + leucovorin $(16.78 \mu \mathrm{g} / \mathrm{ml}+$ $391 \mathrm{ng} / \mathrm{ml}$ respectively), FOLFOX (oxaliplatin $2.58 \mu \mathrm{g} / \mathrm{ml}+5$ FU $16.78 \mu \mathrm{g} / \mathrm{ml}+$ leucovorin $391 \mathrm{ng} / \mathrm{ml}$ ), FOLFIRI (irinotecan $4 \mu \mathrm{g} / \mathrm{ml}+5-\mathrm{FU} 16.78 \mu \mathrm{g} / \mathrm{ml}+$ leucovorin $391 \mathrm{ng} / \mathrm{ml})$, and cetuximab (184 $\mu \mathrm{g} / \mathrm{ml})$ (29). DMSO was used as control for the drug sensitivity test. Experiments were performed in triplicate for statistical significance and results plotted as percent viability for each treatment group.

\section{Proteasome Activity Measurements}

Proteasome 20S activity kit (Sigma-Aldrich, Cat. No. MAK172) was used to measure the proteasome activity of $\mathrm{MBC} 02$ and HCT116 cells. 80,000 cells were seeded in each well of a 24 well plate and allowed to adhere overnight. Proteasome substrate stock and proteasome assay loading solution were prepared following the manufacturer's protocol. Media was removed and replaced with a 1:1 ratio of complete media and proteasome assay loading solution and incubated at $37^{\circ} \mathrm{C}, 5 \% \mathrm{CO}_{2}$ and 95\% humidity for $4 \mathrm{~h}$ in the dark. Following incubation, the fluorescence intensity was measured at an excitation wavelength $\left(\lambda_{\text {ex }}\right)$ of $490 \mathrm{~nm}$ and an emission wavelength $\left(\lambda_{\mathrm{em}}\right)$ of $525 \mathrm{~nm}$. For the proteasome inhibition assay, cells were grown to $\sim 85-$ $90 \%$ confluency in $10 \mathrm{~cm}$ dishes. Bortezomib was used at a concentration of $200 \mathrm{nM}$ to treat cells for different time points ranging from $30 \mathrm{~min}$ to $2 \mathrm{~h}$. Untreated cells were used as control in the proteasome inhibition assay.

\section{Statistical Analysis}

All quantitative data are represented as mean \pm SEM, calculated from at least three independent biological replicates. Statistical significance was calculated using the Student's $t$-test. $P<0.05$ was considered statistically significant. GraphPad PRISM (San Diego, CA) software was used for creating all graphs.

\section{RESULTS}

\section{Primary Tumor Histology}

Clinical diagnosis of the primary tumor revealed stage IIIA disease $\left(\mathrm{T}_{2} \mathrm{~N}_{1} \mathrm{M}_{0}\right)$, indicating that the cancer may have progressed into the nearby submucosal tissue and into atleast 3 lymph nodes, although it had not metastasized to distant sites. Histopathological evaluation of hematoxylene-eosin (H\&E) stained sections of the primary tumor demonstrated moderate differentiation with cancer cells forming irregular glandular structures. Cancer cells were marked by the dark purple staining of the nuclei (Figure 1A). Strong Ki67 staining in regions of the tumor showed the presence of actively dividing cancer cells (Figure 1B). Upon investigation we also observed an abundant $\beta$-catenin expression in the primary tumor (Figure 1C).

\section{Preliminary Characterization and Cytogenetic Analysis of MBC02}

We have developed a novel cell line, MBC02, from the primary tumor site of a 37-year-old female Indian CRC patient. As controls established colorectal cancer cell linesHCT116, HT29, and SW620 were used. HCT116 and HT29 were obtained from primary carcinomas of an adult Caucasian male and female patient respectively, whereas, SW620 was derived from a metastatic tumor of a male Caucasian patient ${ }^{1}$.

${ }^{1}$ https://www.atcc.org 


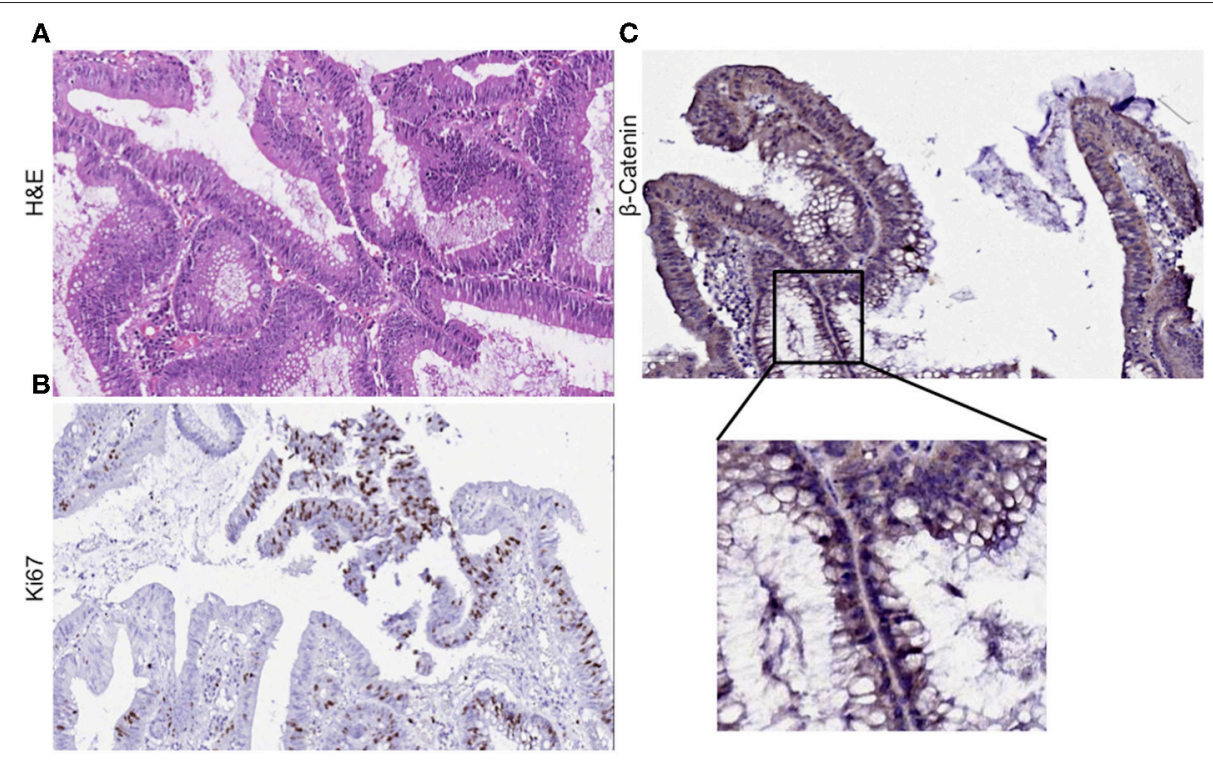

FIGURE 1 | Histological evaluation of primary tumor. (A) H\&E staining of the primary tumor show moderate differentiation. Cancer cells form irregular glandular structures. (B) Ki67 positive staining mark the regions of actively dividing cancer cells within the tumor. (C) Primary tumor section was found to express $\beta$-catenin abundantly.

Microscopic examination of passage 10 and 17 under low and high magnification (10X and 40X) revealed that $\mathrm{MBC} 02$ cells grew as a monolayer that was strongly adherent to the substratum with a flattened morphology that is characteristic of epithelial cells (Figures 2A,B). Immunofluorescence staining using anti-tubulin antibody further highlighted the epithelial morphology of these cells (Figures 2C,D). Since MBC02 cell line was not derived by clonal selection, the presence of a heterogenous population is apparent with some cells being larger. The average population doubling time for $\mathrm{MBC} 02$ was calculated to be approximately $24 \mathrm{~h}$ (Figure 3A). In comparison, average population doubling time for HCT116, HT29, and SW620 were calculated to be 20, 25, and $28 \mathrm{~h}$, respectively (Figure S1).

Karyotype analysis of MBC02 cells revealed chromosomal instability in almost all cells. These cells were near-tetraploid with a modal chromosome count of 89. Significant numerical and gross structural abnormalities were observed in chromosomes, some of which were present in multiple copies. A few of the structural rearrangements observed were centric fission detected in one or more copies of chromosome 1, deletion of the short arm of chromosome 1, 2, 4, 5, 11, and 12 and deletion of the long arm of chromosome 2, 9, and 19. In addition, derivative chromosomes as a result of addition of material of unknown origin, probably via translocation, were observed in one or more copies of the long arm of chromosomes 18, 19, 20,21, and 22 as well as in the short arm of chromosome 19 (Figure 3B). Of note, HCT116 cells are reported to be near-diploid with modal chromosome number of 45 whereas HT29 and SW620 cells are hypertriploid (modal chromosome number of 71) and hyperdiploid (modal chromosomal number of 50), respectively ${ }^{1}$. Cytogenetic analysis of two different passages of MBC02 cells (passage 8 and 16) yielded identical results indicating that the integrity of the cell line is preserved between early and late passages. The abnormal karyotype could have resulted from gross defects in mitosis, both at early and late stages of cell division as well as during cytokinesis. This may lead to the presence of multinucleate cells. Indeed, we observed a $\sim 6$-fold increase in the number of cells with multipolar metaphase spindle in MBC02 as compared to HCT116 (Figure S2). We also observed a $\sim 12$-fold enhancement in the number of multinucleated cells in asynchronous cultures of MBC02 in comparison to HCT116. In addition, about $15 \%$ cells were present in cytokinesis in MBC02 whereas only about $6 \%$ of cells were observed to be undergoing cytokinesis in HCT116 (Figure S3). This 2.5fold increase in the cytokinetic index in $\mathrm{MBC} 02$ could be the result of the presence of centrosomal and spindle defects in these cells (Figure S2). Based on the above results, it is apparent that mitotic defects at both early and late stages of cell division may have contributed toward MBC02 cells to have become aneuploid.

DNA content analysis of asynchronous culture of $\mathrm{MBC} 02$ cells was performed by measuring the fluorescence intensity of propidium iodide incorporated during the various stages of the cell cycle. We observed that $\sim 46 \%$ of cells were at G1 phase representing diploid DNA content $(2 \mathrm{n}) . \sim 24 \%$ cells were at S phase $(>2 n)$ and $\sim 15 \%$ were at the G2/M phase ( $4 n$ ) (Figure $3 C$ ). To study the tumorigenic propensity of $\mathrm{MBC} 02$ cells, we performed anchorage independent growth assay. We observed the appearance of colonies after 2 weeks of plating the cells. The colonies appeared to be small and rounded (Figure 3D). This observation suggested that MBC02 cells have the potential to form tumors if injected into nude or SCID mice and may prove to be a valuable model system for not only studying cancer pathogenesis but also for screening novel therapeutics for clinical use. 

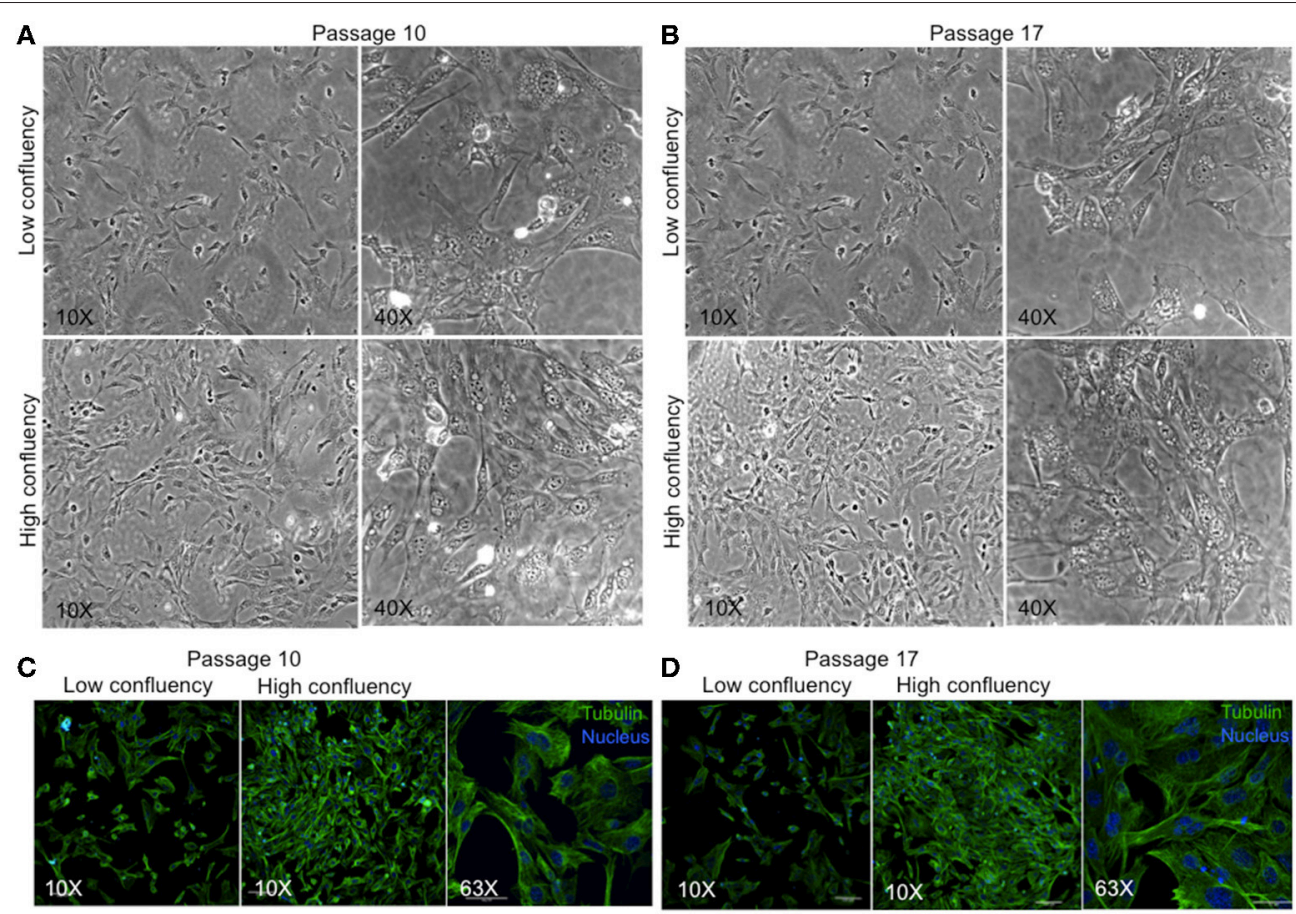

FIGURE 2 | Morphological evaluation of MBC02. (A,B) Phase contrast images of passage 10 and 17 of MBC02 at low (10X) and high (40X) magnification show that these cells are adherent to the substratum and have a flattened morphology similar to epithelial cells. (C,D) Immunofluorescent staining using anti- $\alpha$-tubulin antibody show well-formed cytoskeletal network within these cells. The heterogenous nature of MBC02 cell line is apparent due to the presence of some cells that are larger than others.

\section{A}

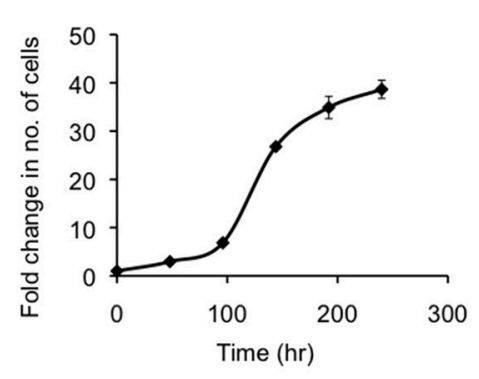

B

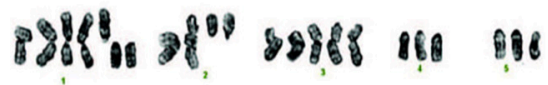

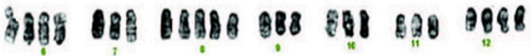

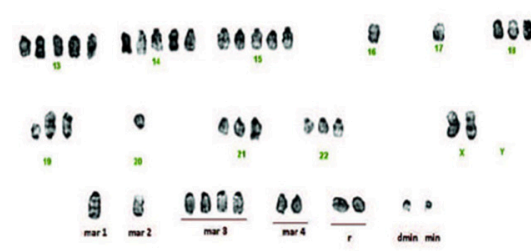

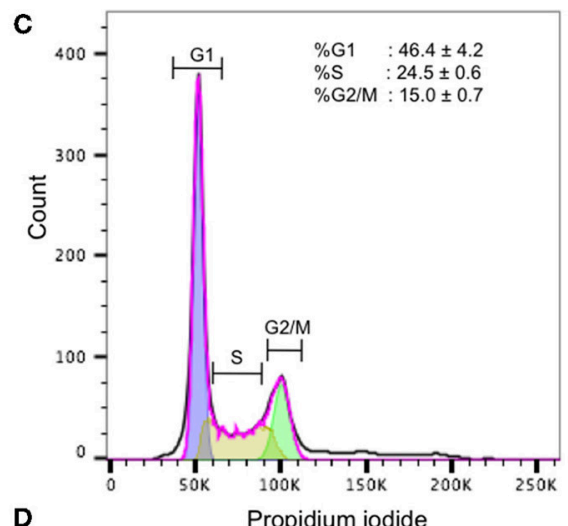

Propidium iodide

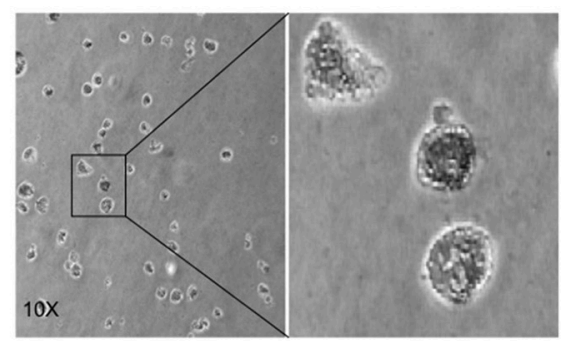

FIGURE 3 | Preliminary characterization of MBC02. (A) Population doubling time of MBC02 culture was calculated to be approximately $24 \mathrm{~h}$. (B) MBC02 cells exhibit gross cytogenetic defects in the form of both structural and numerical aberrations ranging from centric fission, deletions of either long or short arms of more than one chromosome, duplications and complete loss of an arm of more than one chromosome. The modal chromosome number in MBC02 is 89 . (C) DNA content analysis of MBC02 cells revealed $\sim 46 \%$ cells in the G1 phase whereas, $\sim 24$ and $\sim 15 \%$ were in S and G2/M phase of the cell cycle (D) The ability of MBC02 cells to form colonies in soft agar indicate that these cells can proliferate in an anchorage independent manner and may form tumors if injected in mice. 
TABLE 1 | Mutational analysis of MBC02.

\begin{tabular}{lcccccc}
\hline CRC sample & \multicolumn{5}{c}{ KRAS mutation } & $\begin{array}{c}\text { BRAF } \\
\text { mutation } \\
\text { (V600E) }\end{array}$ \\
\cline { 2 - 6 } & Codon 12 & Codon 13 & Codon 61 & Codon 146 & (VT \\
\hline Original tumor & WT & WT & WT & WT & WT \\
MBC02 & WT & WT & WT & WT & WT \\
\hline
\end{tabular}

MBCO2 cells were evaluated for clinically relevant $C R C$ related mutations in KRAS and BRAF. Codons 12, 13, 61, and 146 contained the wild type sequence. The V600E mutation in BRAF was also not present in $\mathrm{MBCO} 2$ cells.

We next examined the original tumor and MBC02 cell line for the presence of common mutations in KRAS (codons 12, 13, 61, and 146) and BRAF (V600E) that are prevalent among CRC patients. Mutations in these genes were not present in either the tumor or the cell line (Table 1). These molecular markers used for the selection of anti-EGFR therapy were preserved in the patient tumor tissue as well as in the tumor derived primary cell line MBC02.

\section{Key Signaling Pathways Are Differentially Regulated in MBC02}

CRC pathogenesis is characterized by mis-regulation of a number of molecular pathways that often crosstalk in a complex network. Of note are the Wnt- $\beta$-catenin, TGF $\beta$ and Notch signaling pathways $(30,31)$. To investigate whether these pathways are differentially regulated in $\mathrm{MBC} 02$ cells in comparison to a standard CRC cell line, HCT116, we quantified the relative mRNA expression of key components of the Wnt- $\beta$-catenin, TGF $\beta$ and Notch signaling pathways. Our comparative findings revealed that several genes from each of the three pathways were overexpressed in MBC02. In the context of the Wnt$\beta$-catenin pathway, all key signaling molecules showed highly upregulated expression, except for the scaffolding protein Axin1 that showed $\sim 4$-fold downregulation as compared to HCT116. A similar trend was observed for the TGF $\beta$ pathway with the highest expression of SMAD4 ( 3,000-fold). The Notch signaling pathway also showed varied expression levels with Notch4 mRNA being 23,000-fold higher in MBC02 (Table 2). Our findings present strong evidence that clinically relevant signaling pathways are differentially regulated in $\mathrm{MBC} 02$, as compared to HCT116.

\section{MBC02 Cells Lack Cell-Cell Contacts and Are Highly Migratory and Invasive}

Altered molecular regulation in a cancer cell resulting in the acquired ability of enhanced cell motility is a key driver in cancer metastasis (9). We set forth to evaluate the relative mRNA expression levels of EMT markers in MBC02 and the established CRC cell lines HCT116, HT29, and SW620. Ecadherin was maximally expressed in HT29 ( 3.5-fold higher than HCT116). In SW620, we observed a decrease in E-cadherin expression and almost no detectable mRNA transcript in MBC02. There was a concomitant elevation of $\mathrm{N}$-cadherin and vimentin expression in MBC02 ( 6-fold and 4,000-fold over HCT116). However, there was a more moderate increase in vimentin expression in MBC02 over SW620 ( 8-folds) (Figure 4A). The
TABLE 2 | Key signaling pathways are mis-regulated in MBC02.

\begin{tabular}{|c|c|c|c|}
\hline Signaling pathway & Gene & $\begin{array}{l}\text { mRNA expression } \\
\text { in } \mathrm{MBC} 02\end{array}$ & $\begin{array}{c}\text { Fold change (over } \\
\text { HCT116) }\end{array}$ \\
\hline \multirow[t]{7}{*}{ Wnt- $\beta$-catenin } & Frizzled & Upregulation & 1,500 \\
\hline & LRP6 & Upregulation & 8,000 \\
\hline & Disheveled & Upregulation & 4,700 \\
\hline & GSK3b & Upregulation & 6,000 \\
\hline & APC & Upregulation & 3,650 \\
\hline & Axin1 & Downregulation & 4 \\
\hline & $\beta$-catenin & Upregulation & 1,800 \\
\hline \multirow[t]{4}{*}{ TGF $\beta$ pathway } & SMAD2 & Upregulation & 1.3 \\
\hline & SMAD 3 & Upregulation & 3.6 \\
\hline & SMAD 4 & Upregulation & 3,000 \\
\hline & SMAD 7 & Upregulation & 13 \\
\hline \multirow[t]{11}{*}{ Notch signaling } & Notch1 & Downregulation & Undetectable \\
\hline & Notch2 & Upregulation & 9,000 \\
\hline & Notch3 & Upregulation & 500 \\
\hline & Notch4 & Upregulation & 23,000 \\
\hline & DLL1 & Downregulation & Undetectable \\
\hline & DLL3 & Downregulation & Undetectable \\
\hline & DLL4 & Upregulation & 2,000 \\
\hline & JAG1 & Downregulation & Undetectable \\
\hline & JAG2 & Upregulation & 50 \\
\hline & HES4 & Upregulation & 6 \\
\hline & HEY1 & Downregulation & Undetectable \\
\hline
\end{tabular}

Differential gene expression in MBCO2 cells was determined using qRT-PCR and fold change in mRNA levels was calculated with respect to HCT116. Important signaling pathways that are critical in CRC pathogenesis are mis-regulated in MBCO2.

lowered expression of E-cadherin coupled with an enhancement in the levels of $\mathrm{N}$-cadherin and vimentin constitute a typical molecular signature for EMT (32), suggesting that $\mathrm{MBC} 02$ may have undergone molecular alterations that could result in its transition from the epithelial to mesenchymal phenotype. Immunofluorescence analysis using an anti-E-cadherin antibody demonstrated localization of E-cadherin at cell-cell junctions in HCT116 as indicated by strong immunofluorescence staining. However, a similar pattern was not seen in MBC02 suggesting a loss of plasma membrane tethered E- cadherin that may have resulted in loss of adherens junction integrity in $\mathrm{MBC} 02$ (Figure 4B). Further, we examined the expression of EMT related transcription factors like Twist and Zeb that play critical roles in tumorigenesis and metastasis (33). There was a significant elevation in the levels of Twist ( $\sim 20$-folds) and Zeb2 ( 5,000folds) in MBC02 as compared to HCT116, while Snail, Slug, and Zeb1 transcripts were undetectable. However, all three transcription factors had elevated expression in SW620 as compared to HCT116 (Figure 4C). Together, these molecular alterations in $\mathrm{MBC} 02$ could be considered as indicators of these cells having undergone at least a partial EMT.

Transition of tumor cells from the epithelial to mesenchymal phenotype endows them with an enhanced capacity for migration. To explore whether there is an enhancement in the motility of $\mathrm{MBC} 02$ cells alongside the presence of the EMT signature, we performed a wound-healing assay. After 

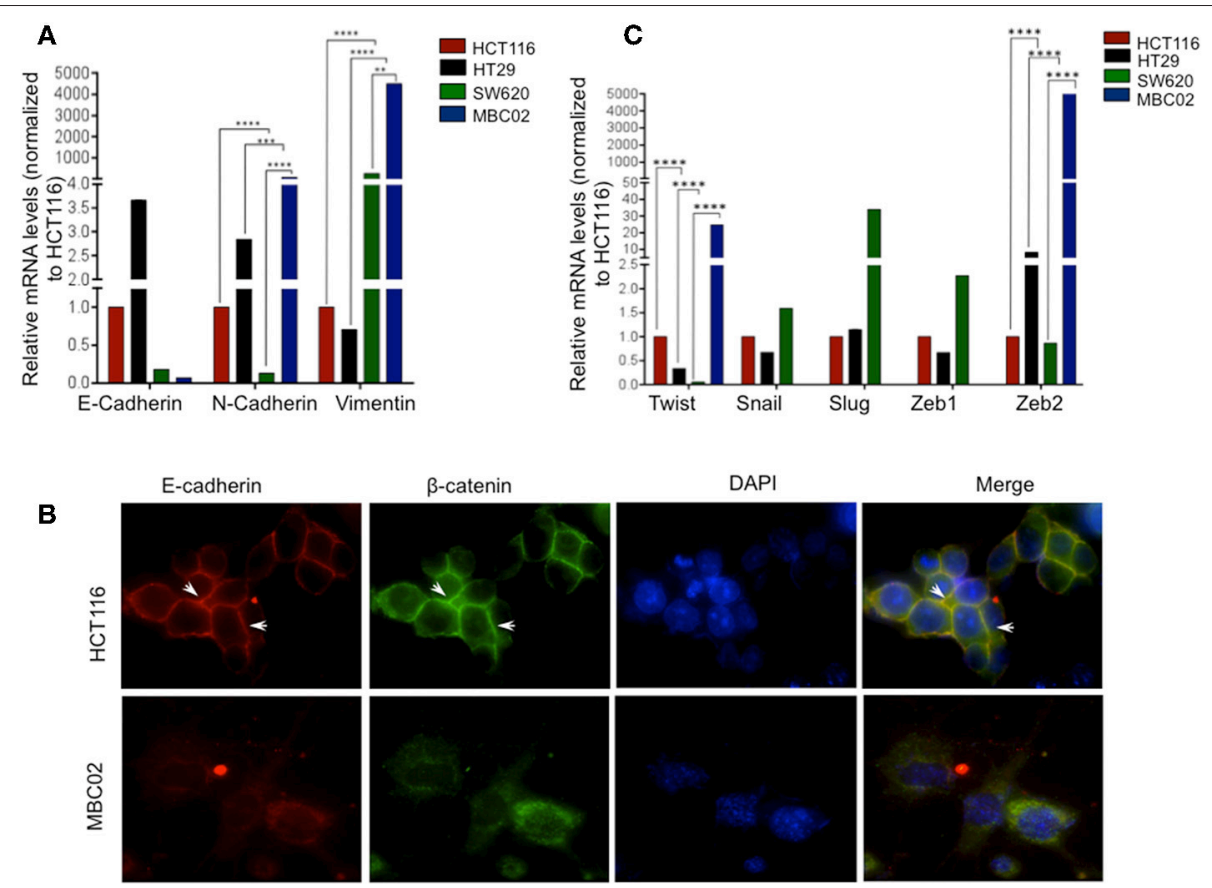

FIGURE 4 | MBC02 exhibits features of epithelial to mesenchymal transition. (A) mRNA expression analysis of CRC cell lines using qRT-PCR shows downregulation of E-cadherin and concomitant upregulation of N-cadherin and vimentin, indicating a cadherin switch in MBC02 and SW620 cell lines. (B) E-cadherin mediated intercellular junctions are lost in MBC02. Immunofluorescence analysis using anti-E-cadherin and anti- $\beta$-catenin antibodies reveal localization of both proteins at the cell-cell junctions in HCT116 (arrowheads), whereas no cortical staining is seen in MBC02. (C) EMT related transcription factors Twist and Zeb2 showed increased expression in MBC02 as compared to HCT116. Additionally, Snail, Slug, and Zeb1 are elevated in SW620. $p$-values are ${ }^{* \star} p<0.01,{ }^{\star \star \star} p<0.001,{ }^{\star \star \star \star} p<0.0001$.

wounding a confluent monolayer of cells, the cells along the wound edge were imaged by microscopy over a $48 \mathrm{~h}$ time period. As compared to HCT116, the rate of wound healing was significantly faster in $\mathrm{MBC} 02$, which led to more rapid healing of wounded monolayers. HCT116 cells reduced the width of the wound to $185 \mu \mathrm{m}$ but MBC02 filled the wound in the same time interval (Figures 5A,B). The enhanced motility of $\mathrm{MBC} 02$ cells was confirmed by evaluating migration through transwell pores after subjecting the cells to a serum gradient for $24 \mathrm{~h}$. SW620 showed $\sim 3.0$-fold higher motility than HCT116, whereas, MBC02 exhibited $\sim 2.5$-fold greater motility than HCT116. HT29 cells hardly showed any migratory potential (Figures 5C,D). Similar results were obtained in an invasion assay when these cells were added to matrigel coated Boyden chambers and allowed to migrate across the matrix along a serum gradient. SW620 and MBC02 cells were highly invasive compared to HCT116 ( 6.5-fold and $\sim 6$-fold higher than HCT116). HT29 did not show any invasive property (Figures 5E,F). These observations indicated that the novel cell line MBC02 is similar to the metastatic cell line, SW620 in the expression pattern of EMT related molecular markers that has resulted in these cells being highly migratory and invasive in nature. Taken together, these results suggest that along with the loss of cell-cell junction integrity, MBC02 cells have gained enhanced migratory ability concomitant with increased invasiveness that present strong evidence of these cells having undergone EMT.

\section{Response to Standard Therapy Is Attenuated in $\mathrm{MBCO} 2$}

Most often, the treatment regimens for $\mathrm{CRC}$ include the nucleoside analog 5-fluorouracil (5-FU) in combination with platinum drugs such as oxaliplatin or topoisomerase I inhibitor irinotecan (34). MBC02 cells were subjected to the various standard treatment regimens for CRC that are currently in clinical practice, namely a combination of 5-FU and leucovorin, FOLFOX (combination of oxaliplatin, 5-FU, and leucovorin), FOLFIRI (combination of oxaliplatin, 5-FU and irinotican) and the epidermal growth factor receptor (EGFR) inhibitor, cetuximab. We found that $\mathrm{MBC} 02$ did not show an appreciable response to any of these treatments (Figure 5G, Table S2). EMT is known to induce acquired drug resistance via multiple mechanisms that are not yet well-understood. Upregulation of Twist has been implicated in resistance to 5-FU and oxaliplatin $(35,36)$. Therefore, activation of EMT not only made MBC02 cells highly migratory and invasive, but also less responsive to standard therapeutic drugs for CRC.

\section{Expression, Mislocalization, and Cytoplasmic Accumulation of $\beta$-Catenin in MBC02}

Misregulation of $\mathrm{Wnt} / \beta$-catenin pathway is a major cause of pathogenesis of CRC and mutations in $\beta$-catenin is often used as a marker for disease prognosis $(24,37,38)$. We compared 


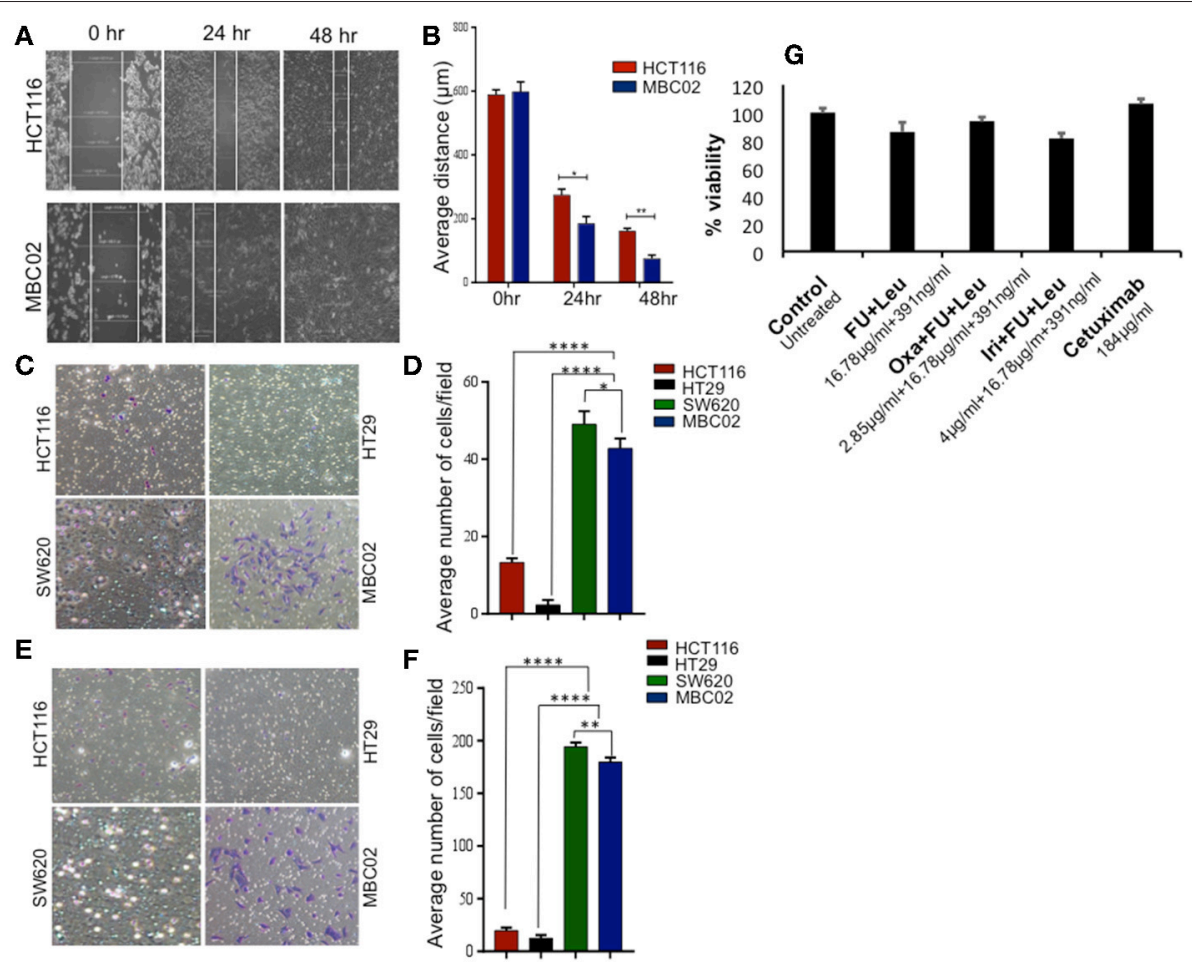

FIGURE $\mathbf{5}$ | MBC02 is highly migratory and invasive and has attenuated response to standard therapy. (A,B) Inherent migratory ability of MBC02 and HCT116 were measured using wound- healing assay. MBC02 cells were able to close the wound within $48 \mathrm{~h}$ whereas the wound still persisted in $\mathrm{HCT} 116$. (C,D) The ability of MBC02 and SW620 cells to migrate through a membrane barrier in a transwell migration assay suggests that MBC02 and SW620 cells have a higher migratory ability as compared to HCT116 and HT29. (E,F) Similar results were obtained in the invasion assay where more number of MBC02 and SW620 cells could cross the matrigel coated membrane barrier compared to HCT116 and HT29. (G) Clinically relevant drug combination including 5-FU, leucovorin, oxaliplatin, irinotecan and cetuximab were tested for efficacy on MBC02 cells. MBC02 did not show any appreciable response to any of the combinations and was similar to that of control. The data is represented as mean \pm SEM calculated from three independent experiments. $p$-values are ${ }^{\star} p<0.05,{ }^{\star \star} p<0.01,{ }^{\star \star \star \star} p<0.0001$.

the expression levels of $\beta$-catenin in MBC02, HCT116, HT29, and SW620 using qRT-PCR analysis. Our results showed a dramatic increase $(\sim 1,500$-fold $)$ in relative expression of $\beta$ catenin mRNA in MBC02 in comparison to all the other cell lines. SW620 however showed similar $\beta$-catenin expression as HCT116 (Figure 6A). As the established cell lines have similar expression of $\beta$-catenin, we have used HCT116 as the control cell line for all further analyses. Immunofluorescence analysis using anti- $\beta$-catenin antibody revealed strong cytoplasmic staining and almost no cortical staining of $\beta$-catenin in MBC02 (Figure 6B). In addition, $\beta$-catenin also localized to the cytoplasmic microtubules but not to the cortical microtubules in MBC02. In contrast, $\beta$-catenin localization at the adherens junctions in HCT116 was confirmed by strong immunofluorescence at the cell-cell contacts (Figure 6B).

The cytosolic accumulation of $\beta$-catenin prompted us to investigate the presence of cancer associated stabilizing mutations in $\mathrm{MBC} 02$ derived $\beta$-catenin. Upon DNA sequence analysis we found that $\mathrm{MBC} 02$ contained the wild type sequence at the S33, S37, T41, and S45 phosphorylation sites. In contrast, HCT116 showed the expected in-frame deletion at S45, as reported earlier (34) (Figure 6C). The presence of the wild type phosphorylation sites in $\beta$-catenin of $\mathrm{MBC} 02$ is indicative of normal phosphorylation. To test this, we immunostained
MBC02 and HCT116 cells using a phospho-specific antibody that recognizes $\beta$-catenin phosphorylated at S33/S37/T41. We observed significant accumulation of phospho- $\beta$-catenin in the cytoplasm and nucleus in $\mathrm{MBC} 02$ confirming that phosphorylation of $\beta$-catenin remained unimpaired (Figure 6D). Interestingly, a significantly higher fraction, $\sim 75 \%$ of $\mathrm{MBC} 02$ cells showed nuclear localization of phospho- $\beta$-catenin as compared to $\sim 20 \%$ for HCT116 (Figure 6E). Upon examination of the mRNA levels of $c-M y c$, a downstream target of $\beta$ catenin activation, we observed a $\sim 1$.5-fold increase in $c$ $M y c$ expression in MBC02 (Figure 6F). These results suggest that cytoplasmic and nuclear accumulation of $\beta$-catenin could partly be responsible for the increased expression of $c-M y c$ in $\mathrm{MBC} 02$.

Upon investigating the subcellular localization of $\beta$-catenin in MBC02 during mitosis, we observed distinct foci of $\beta$ catenin at the spindle poles at metaphase that overlapped with $\alpha$-tubulin (Figure 6G), while during cytokinesis, $\beta$-catenin localized prominently at the inter-cellular bridge (Figure $\mathbf{6 H}$ ). In contrast, the presence of $\beta$-catenin at either the spindle poles or at the inter-cellular bridge was not discernible in HCT116 cells, although cortical $\beta$-catenin staining was prominent (Figures 6G,H). This differential localization of $\beta$-catenin during cell division suggested that the protein may be involved in 

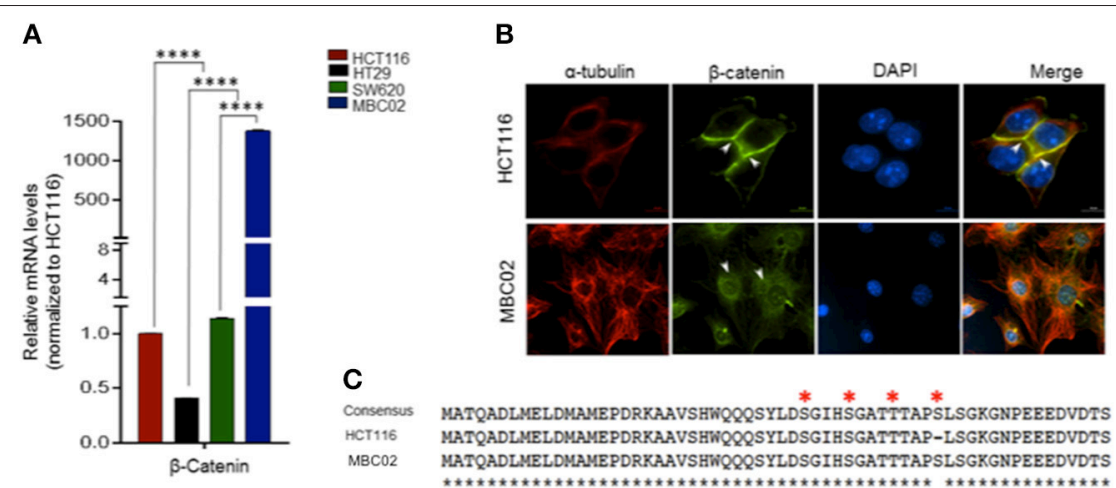
MATQADLMELDMAMEPDRKAAVSHWQQQSYLDSGIHSGATTTAPSLSGKGNPEEEDVDTS

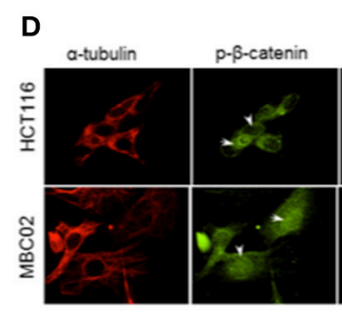

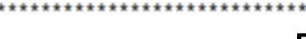
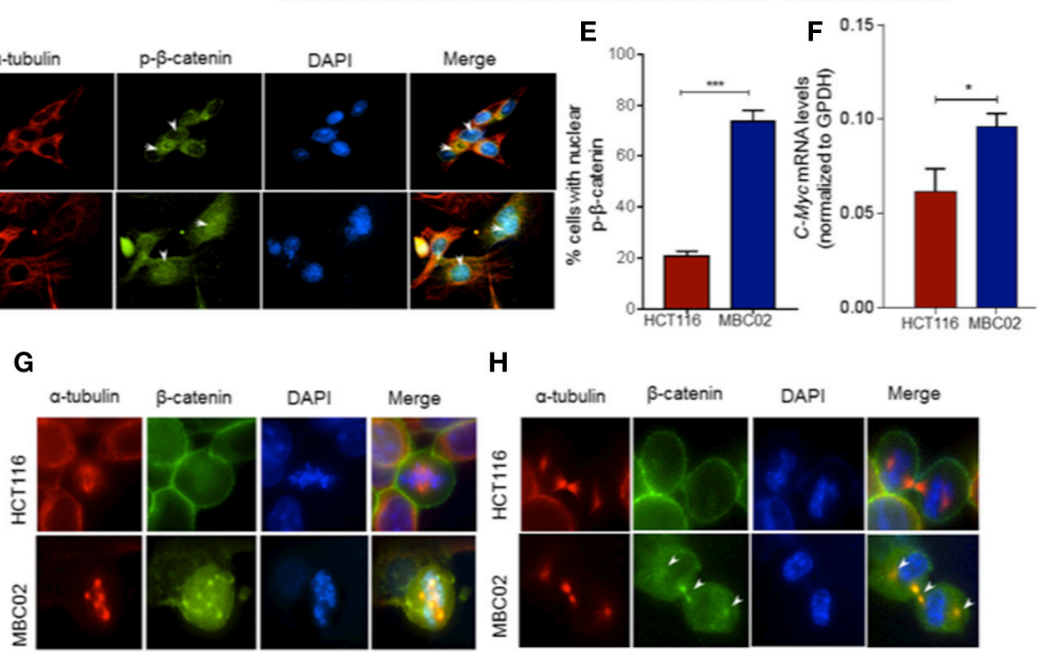

H

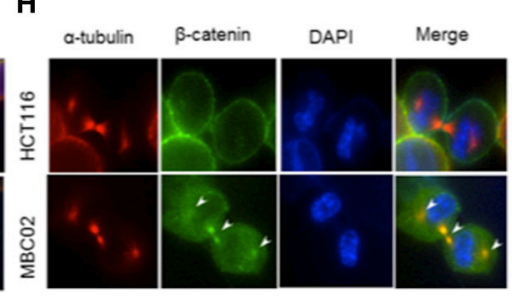

FIGURE 6 | $\beta$-catenin is highly activated in MBC02. (A) Relative mRNA expression of $\beta$-catenin in HCT116, HT29, SW620, and MBC02 cells was measured by RT-PCR and values were normalized to those of HCT116. $\beta$-catenin is highly overexpressed in MBC02 as compared to the other cell lines. (B) Immunofluorescence imaging of subcellular localization of $\beta$-catenin (green) show cortical localization in HCT116, whereas, in MBCO2 it shows predominantly cytoplasmic and nuclear distribution. Arrowheads mark $\beta$-catenin localized to the cortex and at the inter-cellular junctions in HCT116 and cytoplasmic distribution in MBC02. $\alpha$-tubulin (red) and nucleus (blue) are also marked. (C) Sequencing of MBC02 derived $\beta$-catenin shows the N-terminal phosphorylation sites, S33/S37/T41 and S45, contain wild type sequence (red asterisk) whereas in HCT116, there is an in-frame deletion of codon 45. (D) Immunofluorescence imaging confirms the presence of phosphorylated $\beta$-catenin (green) in MBC02 in the cytoplasm and nucleus (arrows). Phosphorylated $\beta$-catenin however, is excluded from the nucleus of HCT116 (arrow). (E) Nearly $75 \%$ of MBC02 cells show presence of phospho- $\beta$-catenin in the nucleus as compared to $20 \%$ HCT116 cells. (F) $\beta$-catenin target gene, $c-M y c$ show elevated expression in MBC02 as compared to HCT116. (G) Prominent localization of $\beta$-catenin (green) at cell cortex is seen in HCT116 during metaphase. There is no visible staining of $\beta$-catenin at the spindle poles in HCT116. MBC02 however shows very prominent $\beta$-catenin localization at the poles of multipolar spindle during metaphase. (H) $\beta$-catenin localizes to the intercellular bridge during cytokinesis in MBC02 marked by arrowheads. In HCT116, $\beta$-catenin is confined to the cell cortex during early (metaphase) and late (cytokinesis) stages of mitosis, as marked by arrowheads. The data is represented as mean \pm SEM calculated from approximately 200 cells per experiment, over three independent experiments. $p$-values are ${ }^{\star} p<0.05,{ }^{\star \star \star} p<0.001,{ }^{\star \star \star \star}$ indicate statistical significance.

distinct roles during different phases of the cell division in $\mathrm{MBC} 02$.

\section{Nuclear Retention of $\beta$-Catenin Could Have Resulted From Elevated Pin1 Expression in MBC02}

The prominent presence of cytoplasmic and nuclear $\beta$-catenin in $\mathrm{MBC} 02$ prompted us to investigate whether alterations in its turnover could result in its enhanced cellular accumulation. Peptidylprolyl Cis/Trans Isomerase, NIMA-interacting 1 (Pin1) is known to cause isomerization induced structural changes in $\beta$-catenin that interferes with its interaction with adenomatous polyposis coli (APC) and thus modulate its turnover (39). We examined the level of expression of Pin1 in $\mathrm{MBC} 02$ to check whether Pin1 could account for the elevated nuclear accumulation of $\beta$-catenin in these cells. Our results demonstrated a dramatic increase of $\sim 9,000$-fold in mRNA expression of Pin1 in $\mathrm{MBC} 02$ (Figure 7A). Western blot analysis of whole cell lysates of HCT116 and MBC02 showed a significant increase $(\sim 3.5$-fold $)$ in Pin 1 protein levels in MBC02 (Figures 7B,C). In addition, we performed western blot analysis of APC on $\mathrm{MBC} 02$ cell lysates to ascertain the presence of APC truncation, which is common in CRC. A band appeared at approximately $\sim 150 \mathrm{KDa}$ size, indicating the presence of a truncated form of APC in $\mathrm{MBC} 02$ in comparison to the full-length protein observed in HCT116 (Figure S4). Taken together, the elevated levels of Pin1 and truncated APC in $\mathrm{MBC} 02$ could be responsible, at least in part, in retaining $\beta$-catenin in the nucleus of MBC02 cells. 

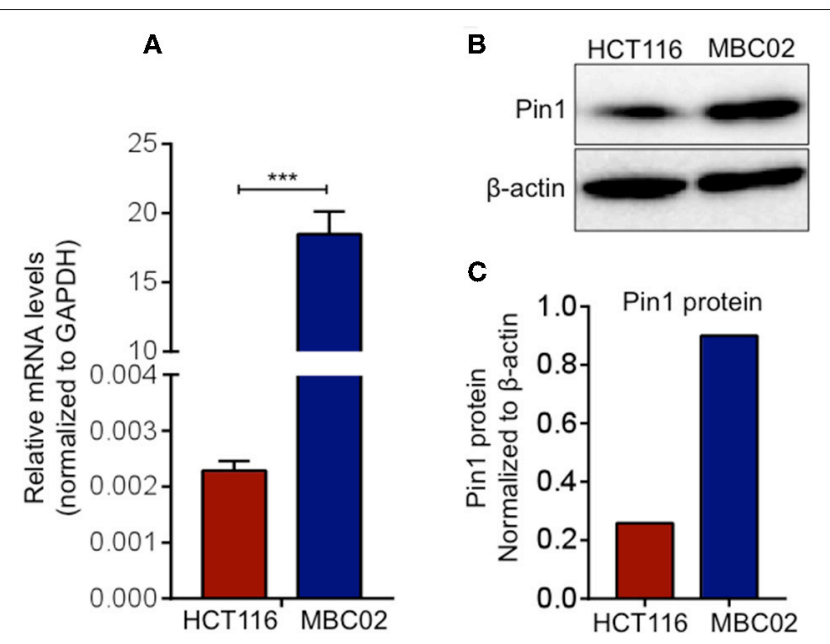

C

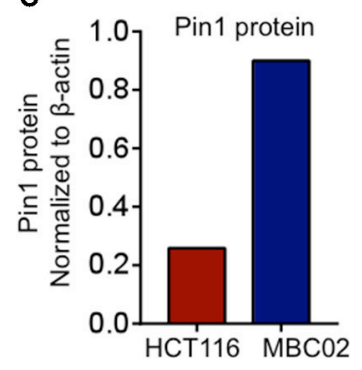

FIGURE 7 | Elevated Pin1 levels in MBC02. (A) qRT-PCR measurement of relative mRNA levels of Pin1 in MBC02 and HCT116 cells show that Pin1 transcript levels are highly elevated in $\mathrm{MBC02}$. (B,C) Western blot analysis corroborates the RT-PCR data and shows about 3.5 fold higher Pin 1 level in MBC02 as compared to HCT116. The data is represented as mean \pm SEM calculated from three independent experiments. $p$-values are ${ }^{\star \star *} p<0.001$.

\section{MBC02 Has Elevated Intrinsic Proteasomal Degradation Activity}

Ubiquitin mediated proteasomal degradation of $\beta$-catenin is a critical step in the overall regulation of the $\mathrm{Wnt} / \beta$-catenin signaling cascade and is brought about by the multiprotein complex called the $26 \mathrm{~S}$ proteasome (22). We postulated that increase in the proteasomal activity could possibly act as a compensatory mechanism for mitigating the high expression of $\beta$-catenin in $\mathrm{MBC} 02$. Evaluation of basal proteasomal activity in $\mathrm{MBC02}$ revealed an almost 6-fold higher proteasome activity in $\mathrm{MBC} 02$ in comparison to HCT116 (Figure 8A). Further, we tested the comparative efficacy of bortezomib, a clinically approved anti-cancer drug that blocks the chymotrypsin activity of the 20S subunit of the proteasome, in MBC02 and HCT116 cells (40-43). A higher $\mathrm{IC}_{50}$ value in $\mathrm{MBC02}(\sim 22 \mathrm{nM})$ as compared to that in HCT116 $(\sim 5 \mathrm{nM})$ showed that $\mathrm{MBC} 02$ is less sensitive to the proteasome inhibitor compared to HCT116 (Figure 8B). To check whether the inactivation of the proteasome mediated protein degradation system could result in the accumulation of cellular $\beta$-catenin, we treated $\mathrm{MBC} 02$ cells with $200 \mathrm{nM}$ of bortezomib, retrieved cells at regular time intervals after commencement of treatment and measured the level of $\beta$-catenin protein using immunoblotting. Bortezomib treated cells accumulated $\beta$-catenin as early as $30 \mathrm{~min}$ post treatment and continued thereafter up to $2 \mathrm{~h}$ (Figure 8C). We further examined whether the buildup of $\beta$-catenin led to alteration in expression of $c-M y c$ in these cells. We observed that there was a 2-fold increase in $c$-Myc mRNA levels in treated cells as compared to control (Figure 8D). Our findings suggest that the enhanced proteasomal activity in $\mathrm{MBC} 02$ partially compensates for the unusually high expression of $\beta$-catenin mRNA. The higher proteasome activity in turn makes MBC02

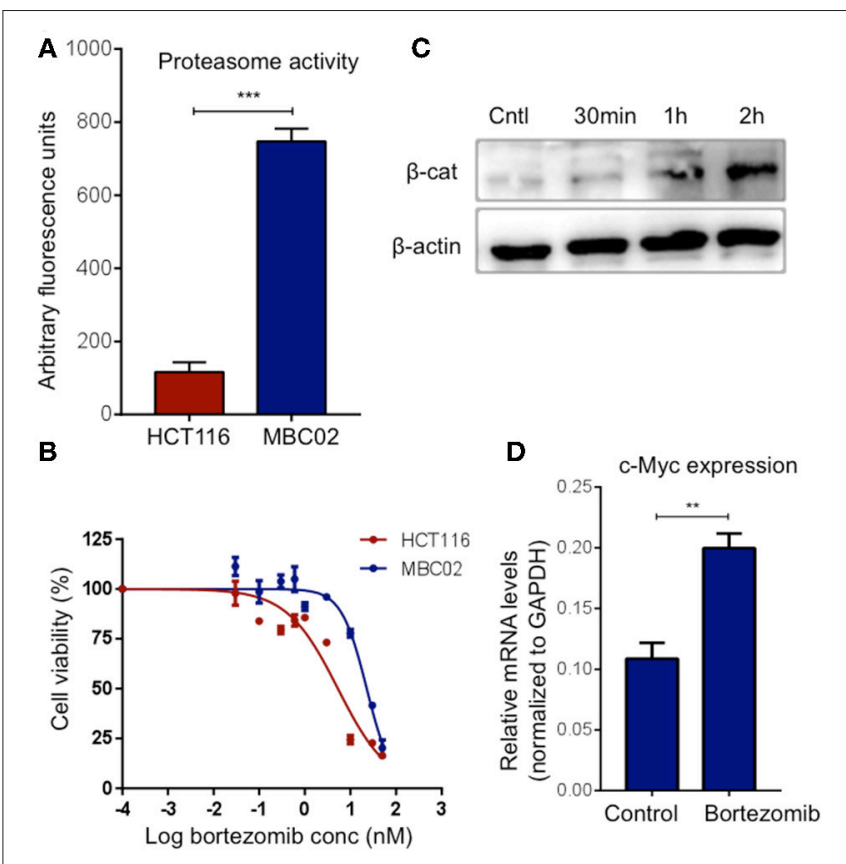

FIGURE 8 | High proteasome activity is observed in MBC02 cells. (A) MBC02 showed $\sim 6.5$ fold higher endogenous proteasome activity as compared to HCT116. (B) MTT assay for checking the cytotoxicity of bortezomib in MBC02 and HCT116 show a higher $\mathrm{IC}_{50}$ value for MBC02 $(\sim 22 \mathrm{nM})$ as compared to HCT116 ( 5 nM), indicating that MBC02 cells are less sensitive to bortezomib. (C) Western blot analysis of cell lysates from bortezomib $(200 \mathrm{nM})$ treated cells shows $\beta$-catenin accumulation as early as 30 min post-treatment, thereafter not increasing appreciably up to $2 \mathrm{~h}$. (D) Relative transcript levels of downstream target of $\beta$-catenin, $c-M y c$, were measured upon treatment with bortezomib (200 nM) and show $\sim 2$ fold increase in mRNA levels as compared to untreated control cells. The data is represented as mean \pm SEM calculated from three independent experiments. $p$-values are ${ }^{* *} p<0.01,{ }^{\star \star *} p<0.001$.

cells less responsive to the proteasome inhibitor, bortezomib. Further, bortezomib-induced inhibition of proteasome activity allows $\beta$-catenin accumulation that brings about transcriptional activation of $c-M y c$.

\section{DISCUSSION}

Cancer cell lines have been the foundation for studies that allow not only elucidation of mechanisms of onset and progression of disease but also contribute toward screening of anticancer molecules for drug development. Patient derived cell lines from cancers originating in specific ethnic groups may potentially be of immense value owing to their inherent population specific genetic variations that ultimately influence disease progression. Although CRC cases are on the rise in India, there is a dearth of Indian patient derived cell lines that can facilitate studies to unravel the characteristics of CRC pathogenesis in the Indian population by serving as a relevant model to study various aspects of disease progression and its subsequent management in the clinic. Intra-tumor heterogeneity (ITH) or the coexistence of genetically distinct sub-clonal populations of cells within the same tumor, is the most defining aspect of all cancers as it 
influences its response to a given therapy. Conventional cell line models fail to capture this heterogeneity of tumors as they are mostly clonal and highly homogenous in nature. In this study, we have established a primary cancer cell line, which is derived from a CRC patient addressing the above problem by propagating polyclonal tumor cells closely resembling the native patient tumor.

We observed morphological differences between $\mathrm{MBC} 02$ and the widely used established CRC cell lines (Figure 2). Gross numerical and structural anomalies in more than one chromosome were noted, indicating global chromosomal instability ( $\mathrm{CIN}$ ) in $\mathrm{MBC} 02$, a feature that is common in $80-85 \%$ of all CRC cases (44) (Figure 3B). The underlying reason could be the presence of multipolar metaphase spindles arising from the supernumerary centrosomes that ultimately result in defective mitosis and cytokinesis in these cells leading to the formation of large number of multinucleate cells (Figures S2, S3). Tumorigenicity of a cell line upon implantation in mice serves as an invaluable tool for testing and developing novel therapeutics. The ability of $\mathrm{MBC} 02$ cells to form colonies in soft agar in an anchorage independent manner (Figure 3D) alludes to its potential to be developed as a colorectal cancer model. The absence of the clinically relevant mutations in KRAS and BRAF (Table 1) in MBC02 suggests that cancer pathogenesis may have been driven by some other mechanism. Pathogenesis and progression of CRC have been associated with mis-regulation of inter-connected signaling pathways, of which Wnt- $\beta$-catenin, TGF $\beta$, and Notch are prominent $(12,45,46)$. These have also been implicated in the activation of the EMT program leading to metastasis, resistance to chemotherapy and poor survival (12). Our indepth analysis of mRNA expression of Wnt- $\beta$-catenin, TGF $\beta$, and Notch pathways highlight the presence of differentially regulated gene expression patterns in $\mathrm{MBC02}$ (Table 2). Aoki et al. (47) demonstrated that activation of $\beta$-catenin/TCF contributed to chromosomal instability (CIN) in many cancers including gastrointestinal malignancies, which is independent of the p53 status. Therefore, taken together, these molecular features sets MBC02 apart from the widely used established CRC cell lines.

Under normal physiological conditions, an optimal level of E-cadherin expression is necessary to maintain structural integrity of the tissue via cell-cell adherens junction formation. In $\mathrm{MBC} 02$, there is a switch from E-cadherin to $\mathrm{N}$-cadherin expression, accompanied by gain of expression of vimentin, along with upregulation of Twist and Zeb2 (Figures 4A,C). These transcription factors have been reported to bind to the E-cadherin promoter and bring about its transcriptional repression (48). Also, a positive correlation has been established between Twist expression, EMT and poor clinical prognosis (49). Therefore, it is reasonable to assume that high levels of these transcription factors may have resulted in reduction of E-cadherin mRNA expression in $\mathrm{MBC02}$. Moreover, there is loss of E-cadherin from the cell-cell junctions in $\mathrm{MBC02}$ (Figure 2B). In a tumor contexture, the functional outcome of this could be the acquired ability of the cancer cells to break off from the tumor mass and metastasize.
MBC02 cells do exhibit an enhanced migratory and invasive nature that is similar to that of the established metastatic CRC cell line SW620 (Figures 5A-F) Therefore, our results demonstrate that the EMT program is likely to be activated in $\mathrm{MBC} 02$.

Recent years have seen EMT emerge as one of the major determinants of response to chemotherapy with clear correlation between the EMT phenotype and diminished efficacy of chemotherapeutic agents (50). The standard-of-care treatment regimen for CRC consisting either of a combination of 5-FU and leucovorin, FOLFOX, FOLFIRI or the targeted therapy cetuximab did not have any appreciable effect on these cells (Figure 5G). Although the mechanisms governing EMT induced drug resistance are not well-understood, several molecules are implicated to have key contributions, including EMT transcription factors Twist and Zeb (51). In addition to transcriptional repression of E-cadherin, these molecules also influence drug response $(11,52,53)$. Low Twist and Zeb expression have shown favorable treatment outcome in patients and therefore, these could be valuable indicators for predicting drug response (54).

Membrane tethered E-cadherin anchors $\beta$-catenin at the plasma membrane forming a cadherin-catenin complex that not only is a component of functional adherens junctions but also shields $\beta$-catenin from proteasomal degradation (19, 20). Loss of E-cadherin in $\mathrm{MBC02}$ (Figure 4B) may have resulted in compromised cell-cell junctions, releasing $\beta$-catenin into the cytoplasm, hence increasing the cytoplasmic pool of free $\beta$-catenin (Figure 6B). In $\mathrm{MBC02}$, the presence of conserved, wild type residues at the regulatory site of $\beta$-catenin (Figure 6C), as well as immunofluorescence analysis using phospho-specific antibody demonstrate that phosphorylated $\beta$ catenin is present in abundance in both cytosolic and nuclear compartments (Figures 6D,E). This observation is supported by the work that showed that $\mathrm{N}$-terminally phosphorylated $\beta$-catenin does not associate with cadherins and is mainly cytosolic and that T41/S45 phosphorylated $\beta$-catenin is largely nuclear (55). Wild type S45 along with S33/S37/T41 ensures efficient phosphorylation that localizes phospho- $\beta$-catenin to the nucleus, as confirmed by immunofluorescence analysis of MBC02. HCT116 however, contains a mutation at the S45 site $(\Delta S 45)$, precluding phosphorylation at that site and excluding $\beta$-catenin from localizing to the nucleus (Figures 6D,E). The cytoplasmically accumulated $\beta$-catenin eventually translocates into the nucleus to bring about transcriptional activation of target genes as seen by the elevated expression of $c-M y c$ in $\mathrm{MBC} 02$ (Figure 6F).

Our observation that $\beta$-catenin is present at the centrosomes in $\mathrm{MBC} 02$ (Figures $\mathbf{6 G}, \mathbf{H}$ ) is supported by earlier studies that have brought forth a relatively novel function of $\beta$-catenin in maintaining centrosomal integrity. Further, overexpression of $\beta$ catenin has been reported to result in disorganized centrosomes and loss of centrosomal cohesion leading to spindle organization defects $(56,57)$. The massive upregulation of $\beta$-catenin in $\mathrm{MBC} 02$ could be responsible for its prominent localization at the spindle poles and the cytokinetic bridge (Figures 6G, $\mathbf{H}$ ). Although localization of $\beta$-catenin to the inter-cellular bridge 
during late telophase has been reported earlier, its function in cytokinesis or its role in inducing cytokinetic defects has not been documented (57). It may be speculated that the increased amount of $\beta$-catenin within a localized area may perhaps play a role in inducing cytokinetic defects that may eventually lead to increase in the overall number of multinucleate cells in MBC02 (Figure S3).

Malignant transformations often lead to changes in the regulation of $\beta$-catenin turnover and result in abnormal accumulation in subcellular compartments (26, 27). Apart from being a core component of the destruction complex, the protein APC plays a crucial role in nuclear export of $\beta$-catenin. Phosphorylation dependent binding of Pin 1 to $\beta$ catenin at the pS247P (phospho-Serine 247-Proline 248) motif brings about structural isomerization of $\beta$-catenin and prevents binding of APC to $\beta$-catenin. Pin1 upregulation has been reported in CRC and has been positively correlated with $\beta$ catenin expression (58-62). Most cancer-related mutations in APC occur within the Mutation Cluster Region (MCR) of APC that produces a N-terminal trunctated protein $(\sim 150$ $\mathrm{KDa}$, instead of the full-length $310 \mathrm{KDa}$ protein) which is unable to bind $\beta$-catenin and mark it for ubiquitination and subsequent proteasomal degradation (50). The elevated Pin1 levels in $\mathrm{MBC} 02$ (Figures 7A-C), together with truncated APC (Figure S4) could have a negative influence on the binding of $\beta$-catenin to APC, thereby inhibiting its nuclear export resulting in the accumulation of $\beta$-catenin in the nucleus (Figure 6D).

The ubiquitin-proteasome machinery plays an important role in maintaining cellular homeostasis by regulating the constant flux of synthesis, degradation and re-synthesis of proteins in the cellular milieu. Cancer cells have evolved various mechanisms to counter the abnormal production of proteins-altered proteasomal activity is one such mechanism $(63,64)$. MBC02 has approximately 6-fold higher basal proteasome activity over HCT116 (Figure 8A) and bortezomib mediated blocking of the proteasome led to a rapid accumulation of $\beta$-catenin (Figure 8C). However, it is unclear whether the high intrinsic proteasomal activity in $\mathrm{MBC} 02$ is a result of the dramatic transcriptional upregulation of $\beta$-catenin or the increased $\beta$-catenin mRNA level is a countermeasure for the elevated proteasomal activity in this cell line.

Proteasomal degradation of $\mathrm{N}$-terminally phosphorylated $\beta$ catenin is well-documented $(26,27)$. Recently, it has been established that phosphorylation of $\beta$-catenin at S33/S37/T41 can also be achieved by NIMA-related protein kinase 2 (Nek2) and that binding of Nek2 to $\beta$-catenin prevents interaction of $\beta$-catenin with the $\mathrm{E} 3$ ligase $\beta$ - TrCP resulting in inhibition of ubiquitination and proteasomal degradation (65). However, it is yet to be established whether Nek2 mediated phosphorylation of $\beta$-catenin is a mechanism that could shield $\beta$-catenin from GSK3 $\beta$ mediated phosphorylation and proteolytic degradation. It has been proposed that Nek 2 mediated phosphorylation may be an alternate regulatory mechanism that could influence $\beta$-catenin stability that is independent of GSK3 $\beta$ (66). For our immunofluorescence analysis, we have used a phospho-S33/S37/T41 specific antibody that is unable to distinguish between the GSK3 $\beta$ or Nek2 mediated phosphorylated forms. We therefore speculate that in addition to the GSK3 $\beta$ mediated phospho- $\beta$-catenin, there may be a significant pool of Nek2 mediated phospho- $\beta$-catenin present that may escape proteasomal degradation and hence accumulate in the cytoplasm in MBC02.

Recent advances focusing on dissecting the molecular dynamics that govern cancer onset and progression are based on studies originating in the western countries with little or no data on Indian patients. India is known to be a genetically diverse population (4), therefore it may be reasonable to speculate that there may be differences in the underlying mechanisms of disease onset. Small molecular perturbations at the genetic level may translate to more drastic mechanistic differences, which could result in currently available therapies being rendered suboptimal in treating patients from various populations. Such molecular differences have the potential to be harnessed for developing either as molecular markers or targeted therapeutics that could be more effective in certain populations. Comparison of $\mathrm{MBC} 02$ cell line, originating from Indian patient, with the established Caucasian cell lines such as HCT116, HT29 and SW620, highlight such differences that may indicate underlying mechanistic differences in pathogenesis of CRC in these populations. However, detailed analyses from large patient cohorts would be needed in order to validate these findings that could be further utilized to design specific drugs tailored to targeted patient groups.

\section{AUTHOR CONTRIBUTIONS}

SM characterized MBC02, performed the cell-based assays, molecular characterization, high-resolution fluorescence imaging, and wrote the manuscript. HK performed the DNA sequencing and Western blot analysis. SK performed the MTT assays for determining the IC50 values. LS performed the anchorage independent growth assay. MJ performed the combinatorial drug sensitivity assay. $\mathrm{AB}$ developed the primary cell line along with initial characterization. $\mathrm{MB}$ performed immuno-histochemical analysis and reporting for the original colorectal tumor tissue. SVSM critically reviewed the manuscript and gave technical inputs on experimental design. MR supervised the design and execution of the experiments and data analysis. $\mathrm{MR}$ and $\mathrm{AD}$ supervised the overall study.

\section{ACKNOWLEDGMENTS}

We thank Dr. Pradip K. Majumder for critical comments on the manuscript. We also thank Rohini S. Nair for technical contribution toward generating $\mathrm{MBC} 02$.

\section{SUPPLEMENTARY MATERIAL}

The Supplementary Material for this article can be found online at: https://www.frontiersin.org/articles/10.3389/fonc. 2019.00054/full\#supplementary-material 


\section{REFERENCES}

1. Arnold M, Sierra MS, Laversanne M, Soerjomataram I, Jemal A, Bray F. Global patterns and trends in colorectal cancer incidence and mortality. Gut (2017) 66:683-91. doi: 10.1136/gutjnl-2015-310912

2. Sirohi B, Shrikhande SV, Perakath B, Raghunandharao D, Julka PK, Lele $\mathrm{V}$, et al. Indian council of medical research, consensus document for management of colorectal cancer. (2014) Indian J Med Paediatr Oncol. 35:192-6. doi: 10.4103/0971-5851.142031

3. Patil PS, Saklani A, Gambhire P, Mehta S, Engineer R, De'Souza A, et al. Colorectal cancer in India: an audit from a tertiary center in a low prevalence area. Indian J Surg Oncol. (2017) 8:484-90. doi: 10.1007/s13193-017-0655-0

4. Xing J, Watkins WS, Hu Y, Huff CD, Sabo A, Muzny DM, et al. Genetic diversity in India and the inference of Eurasian population expansion. Genome Biol. (2010) 11:R113. doi: 10.1186/gb-2010-11-11-r113

5. Fearon EF, Vogelstein B. A genetic model for colorectal tumorigenesis. Cell (1990) 61:759-67. doi: 10.1016/0092-8674(90)90186-I

6. Drewes JL, Housseau F, Sears CL. Sporadic colorectal cancer: microbial contributors to disease prevention, development and therapy. $\mathrm{Br} J$ Cancer (2016) 115:273-80. doi: 10.1038/bjc.2016.189

7. Kinzler KW, Vogelstein B. Lessons from hereditary colorectal cancer. Cell (1996) 87:159-70. doi: 10.1016/S0092-8674(00)81333-1

8. Vu T, Datta PK. Regulation of EMT in colorectal cancer: a culprit in metastasis. Cancers (2017) 9:171. doi: 10.3390/cancers9120171

9. Kalluri R, Weinberg RA. The basics of epithelial-mesenchymal transition. $J$ Clin Invest. (2009) 119:1420-8. doi: 10.1172/JCI39104

10. Bhowmick NA, Neilson EG, Moses HL. Stromal fibroblasts in cancer initiation and progression. Nature (2004) 432:332-7. doi: 10.1038/nature03096

11. Lamouille S, Xu J, Derynck R. Molecular mechanisms of epithelialmesenchymal transition. Nat Rev Mol Cell Biol. (2014) 15:178-96. doi: $10.1038 / \mathrm{nrm} 3758$

12. Chaffer CL, San Juan BP, Lim E, Weinberg RA. EMT, cell plasticity and metastasis. Cancer Metastasis Rev. (2016) 35:645-54. doi: 10.1007/s10555-016-9648-7

13. Espinoza I, Miele L. Deadly crosstalk: notch signaling at the intersection of EMT and cancer stem cells. Cancer Lett. (2013) 341:41-5. doi: 10.1016/j.canlet.2013.08.027

14. Wang Z, Li Y, Kong D, Sarkar FH. The role of Notch signaling pathway in epithelial-mesenchymal transition [EMT] during development and tumor aggressiveness. Curr Drug Targets (2010) 11:745-51.

15. Chaw SY, Abdul Majeed A, Dalley AJ, Chan A, Stein S, Farah CS. Epithelial to mesenchymal transition (EMT) biomarkers-E-cadherin, beta-catenin, APC and Vimentin-in oral squamous cell carcinogenesis and transformation. Oral Oncol. (2012) 48:997-1006. doi: 10.1016/j.oraloncology.2012.05.011

16. Valenta T, Hausmann $G$, Basler K. The many faces and functions of $\beta$-catenin. EMBO J. (2012) 31:2714-36. doi: 10.1038/emboj.2012.150

17. Weis WI, Nelson WJ. Re-solving the cadherin-catenin-actin conundrum. $J$ Biol Chem. (2006) 281:35593-7. doi: 10.1074/jbc.R600027200

18. Basu S, Haase G, Ben-Ze'ev A. Wnt signaling in cancer stem cells and colon cancer metastasis. F1000Res. (2016) 5:F1000. doi: 10.12688/f1000research.7579.1

19. Hinck L, Näthke IS, Papkoff J, Nelson WJ. Dynamics of cadherin/catenin complex formation: novel protein interactions and pathways of complex assembly. J Cell Biol. (1994) 125:1327-40.

20. Huber AH, Weis WI. The structure of the beta-catenin/E-cadherin complex and the molecular basis of diverse ligand recognition by beta-catenin. Cell (2001) 105:391-402. doi: 10.1016/S0092-8674(01)00330-0

21. Wong SHM, Fang CM, Chuah LH, Leong CO, Ngai SC. E-cadherin: its dysregulation in carcinogenesis and clinical implications. Crit Rev Oncol Hematol. (2018) 121:11-22. doi: 10.1016/j.critrevonc.2017. 11.010

22. Hagen T, Vidal-Puig A. Characterisation of the phosphorylation of betacatenin at the GSK-3 priming site Ser45. Biochem Biophys Res Commun. (2002) 294:324-8. doi: 10.1016/S0006-291X(02)00485-0

23. Chisanga D, Keerthikumar S, Pathan M, Ariyaratne D, Kalra H, Boukouris $\mathrm{S}$, et al. Colorectal cancer atlas: an integrative resource for genomic and proteomic annotations from colorectal cancer cell lines and tissues. Nucleic Acids Res. (2016) 44:D969-74. doi: 10.1093/nar/gkv1097
24. Polakis P. The oncogenic activation of beta-catenin. Curr Opin Genet Dev. (1999) 9:15-21. doi: 10.1016/S0959-437X(99)80003-3

25. Morin PJ, Sparks AB, Korinek V, Barker N, Clevers H, Vogelstein $\mathrm{B}$, et al. Activation of beta-catenin-Tcf signaling in colon cancer by mutations in beta-catenin or APC. Science (1997) 275:1787-90. doi: $10.1126 /$ science.275.5307.1787

26. Bilic J, Huang YL, Davidson G, Zimmermann T, Cruciat CM, Bienz M, et al. Wnt induces LRP6 signalosomes and promotes dishevelled-dependent LRP6 phosphorylation. Science (2007) 316:1619-22. doi: 10.1126/science.1137065

27. Gerlach JP, Emmink BL, Nojima H, Kranenburg O, Maurice MM. Wnt signalling induces accumulation of phosphorylated $\beta$-catenin in two distinct cytosolic complexes. Open Biol. (2014) 4:140120. doi: 10.1098/rsob.140120

28. Brijwani N, Jain M, Dhandapani M, Zahed F, Mukhopadhyay P, Biswas M, et al. Rationally co-targeting divergent pathways in KRAS wild-type colorectal cancers by CANscript technology reveals tumor dependence on Notch and Erbb2. Sci Rep. (2017) 7:1502. doi: 10.1038/s41598-017-01566-x

29. Majumder B, Baraneedharan U, Thiyagarajan S, Radhakrishnan P, Narasimhan $H$, Dhandapani $M$, et al. Predicting clinical response to anticancer drugs using an ex vivo platform that captures tumour heterogeneity. Nat Commun. (2015) 6:6169. doi: 10.1038/ncomms7169

30. Brattain MG, Fine WD, Khaled FM, Thompson J, Brattain DE. Heterogeneity of malignant cells from a human colonic carcinoma. Cancer Res. (1981) 41:1751-6.

31. Colussi D, Brandi G, Bazzoli F. Molecular pathways involved in colorectal cancer: implications for disease behavior and prevention. Int J Mol Sci. (2013) 14:16365-85. doi: 10.3390/ijms140816365

32. Gheldof A, Berx G. Cadherins and epithelial-to-mesenchymal transition. Prog Mol Biol Transl Sci. (2013) 116:317-36. doi: 10.1016/B978-0-12-394311-8.00014-5

33. Zhang P, Wei Y, Wang L, Debeb BG, Yuan Y, Zhang J, et al. ATMmediated stabilization of ZEB1 promotes DNA damage response and radioresistance through CHK1. Nat Cell Biol. (2014) 16:864-75. doi: 10.1038/ ncb3013

34. Chilov D, Sinjushina N, Rita H, Taketo MM, Mäkelä TP, Partanen J. Phosphorylated $\beta$-catenin localizes to centrosomes of neuronal progenitors and is required for cell polarity and neurogenesis in developing midbrain. Dev Biol. (2011) 357:259-68. doi: 10.1016/j.ydbio.2011.06.029

35. Cortez MA, Valdecanas D, Zhang X, Zhan Y, Bhardwaj V, Calin GA, et al. Therapeutic delivery of miR-200c enhances radiosensitivity in lung cancer. Mol Ther. (2014) 22:1494-503. doi: 10.1038/mt.2014.79

36. Mårtensson A, Oberg A, Jung A, Cederquist K, Stenling R, Palmqvist R. Betacatenin expression in relation to genetic instability and prognosis in colorectal cancer. Oncol Rep. (2007) 17:447-52. doi: 10.3892/or.17.2.447

37. López-Knowles E, Zardawi SJ, McNeil CM, Millar EK, Crea P, Musgrove EA, et al. Cytoplasmic localization of beta-catenin is a marker of poor outcome in breast cancer patients. Cancer Epidemiol Biomarkers Prev. (2010) 19:301-9. doi: 10.1158/1055-9965.EPI-09-0741

38. Ilyas M, Tomlinson IP, Rowan A, Pignatelli M, Bodmer WF. Beta-catenin mutations in cell lines established from human colorectal cancers. Proc Natl Acad Sci USA. (1997) 94:10330-4.

39. Cheng CW, Leong KW, Tse E. Understanding the role of PIN1 in hepatocellular carcinoma. World J Gastroenterol. (2016) 22:9921-32. doi: 10.3748/wjg.v22.i45.9921

40. Richardson PG, Hideshima T, Anderson KC. Bortezomib (PS-341): a novel, first-in-class proteasome inhibitor for the treatment of multiple myeloma and other cancers. Cancer Control. (2003) 10:361-9. doi: $10.1177 / 107327480301000502$

41. Roccaro AM, Vacca A, Ribatti D. Bortezomib in the treatment of cancer. Recent Pat Anticancer Drug Discov. (2006) 1:397-403. doi: 10.2174/157489206778776925

42. McBride A, Ryan PY. Proteasome inhibitors in the treatment of multiple myeloma. Expert Rev Anticancer Ther. (2013) 13:339-58. doi: 10.1586/era.13.9

43. Wu WK, Cho CH, Lee CW, Wu K, Fan D, Yu J, et al. Proteasome inhibition: a new therapeutic strategy to cancer treatment. Cancer Lett. (2010) 293:15-22. doi: 10.1016/j.canlet.2009.12.002

44. Mármol I, Sánchez-de-Diego C, Pradilla Dieste A, Cerrada E, Rodriguez Yoldi MJ. Colorectal carcinoma: a general overview and future perspectives in colorectal cancer. Int J Mol Sci. (2017) 18:197. doi: 10.3390/ijms18010197 
45. Zhang J, Tian XJ, Xing J. Signal transduction pathways of EMT induced by TGF- $\beta$, SHH, and WNT and their crosstalks. J Clin Med. (2016) 5:E41. doi: $10.3390 /$ jcm 5040041

46. Zi Z, Chapnick DA, Liu X. Dynamics of TGF- $\beta /$ SMAD signaling. FEBS Lett. (2012) 586:1921-8. doi: 10.1016/j.febslet.2012.03.063

47. Aoki K, Aoki M, Sugai M, Harada N, Miyoshi H, Tsukamoto T, et al. Chromosomal instability by beta-catenin/TCF transcription in APC or beta-catenin mutant cells. Oncogene (2007) 26:3511-20. doi: 10.1038/sj.onc. 1210141

48. Vesuna F, van Diest P, Chen JH, Raman V. Twist is a transcriptional repressor of E-cadherin gene expression in breast cancer. Biochem Biophys Res Commun. (2008) 367:235-41. doi: 10.1016/j.bbrc.2007.11.151

49. Ansieau S, Morel AP, Hinkal G, Bastid J, Puisieux A. TWISTing an embryonic transcription factor into an oncoprotein. Oncogene (2010) 29:3173-84. doi: 10.1038/onc.2010.92

50. Voon DC, Huang RY, Jackson RA, Thiery JP. The EMT spectrum and therapeutic opportunities. Mol Oncol. (2017) 11:878-91. doi: 10.1002/1878-0261.12082

51. Brozovic A. The relationship between platinum drug resistance and epithelial-mesenchymal transition. Arch Toxicol. (2017) 91:605-19. doi: 10.1007/s00204-016-1912-7

52. Zhuo WL, Wang Y, Zhuo XL, Zhang YS, Chen ZT. Short interfering RNA directed against TWIST, a novel zinc finger transcription factor, increases A549 cell sensitivity to cisplatin via MAPK/mitochondrial pathway. Biochem Biophys Res Commun. (2008) 369:1098-102. doi: 10.1016/j.bbrc.2008. 02.143

53. Brozovic A, Osmak M. Activation of mitogen-activated protein kinases by cisplatin and their role in cisplatin-resistance. Cancer Lett. (2007) 251:1-16. doi: 10.1016/j.canlet.2006.10.007

54. Sánchez-Tilló E, Siles L, de Barrios O, Cuatrecasas M, Vaquero EC, Castells A, et al. Expanding roles of ZEB factors in tumorigenesis and tumor progression. Am J Cancer Res. (2011) 1:897-912.

55. Maher MT, Mo R, Flozak AS, Peled ON, Gottardi CJ. Betacatenin phosphorylated at serine 45 is spatially uncoupled from beta-catenin phosphorylated in the GSK3 domain: implications for signaling. PLoS ONE. (2010) 5:e10184. doi: 10.1371/journal.pone. 0010184

56. Huang P, Senga T, Hamaguchi M. A novel role of phospho-beta-catenin in microtubule regrowth at centrosome. Oncogene (2007) 26:4357-71. doi: $10.1038 /$ sj.onc. 1210217

57. Polakis P. The many ways of Wnt in cancer. Curr Opin Genet Dev. (2007) 17:45-51. doi: 10.1016/j.gde.2006.12.007

58. Zhu Z, Zhang H, Lang F, Liu G, Gao D, Li B, Liu Y. Pin1 promotes prostate cancer cell proliferation and migration through activationof
Wnt/ $\beta$-catenin signaling. Clin Transl Oncol. (2016) 18:792-7. doi: 10.1007/s12094-015-1431-7

59. Schneider S, Thurnher D, Seemann R, Brunner M, Kadletz L, Ghanim $\mathrm{B}$, et al. The prognostic significance of $\beta$-catenin, cyclin D1 and PIN1 in minor salivary gland carcinoma: $\beta$-catenin predicts overall survival. Eur Arch Otorhinolaryngol. (2016) 273:1283-92. doi: 10.1007/s00405-015-3 609-6

60. Ryo A, Nakamura M, Wulf G, Liou YC, Lu KP. Pin1 regulates turnover and subcellular localization of beta-catenin by inhibiting its interaction with APC. Nat Cell Biol. (2001) 3:793-801. doi: 10.1038/ncb0901-793

61. Henderson BR. Nuclear-cytoplasmic shuttling of APC regulates beta-catenin subcellular localization and turnover. Nat Cell Biol. (2000) 2:653-60. doi: $10.1038 / 35023605$

62. Kim CJ, Cho YG, Park YG, Nam SW, Kim SY, Lee SH, et al. Pin1 overexpression in colorectal cancer and its correlation with aberrant beta-catenin expression. World J Gastroenterol. (2005) 11:5006-9. doi: 10.3748/wjg.v11.i32.5006

63. Datta K, Suman S, Kumar S, Fornace AJ Jr. Colorectal carcinogenesis, radiation quality, and the ubiquitin-proteasome pathway. J Cancer (2016) 7:174-83. doi: 10.7150/jca.13387

64. Chen L, Madura K. Increased proteasome activity, ubiquitin-conjugating enzymes, and eEF1A translation factor detected in breast cancer tissue. Cancer Res. (2005) 65:5599-606. doi: 10.1158/0008-5472.CAN-05-0201

65. Bahmanyar S, Guiney EL, Hatch EM, Nelson WJ, Barth AI. Formation of extra centrosomal structures is dependent on beta-catenin. J Cell Sci. (2010) 123(Pt 18):3125-35. doi: 10.1242/jcs.064782

66. Mbom BC, Siemers KA, Ostrowski MA, Nelson WJ, Barth AI. Nek2 phosphorylates and stabilizes $\beta$-catenin at mitotic centrosomes downstream of Plk1. Mol Biol Cell. (2014) 25:977-91. doi: 10.1091/mbc.E13-06-0349

Conflict of Interest Statement: SM, SK, and MR are employees of Invictus Oncology Pvt. Ltd., and SM and MR hold equity of IOPL.

The remaining authors declare that the research was conducted in the absence of any commercial or financial relationships that could be construed as a potential conflict of interest.

Copyright (c) 2019 Mylavarapu, Kumar, Kumari, Sravanthi, Jain, Basu, Biswas, Mylavarapu, Das and Roy. This is an open-access article distributed under the terms of the Creative Commons Attribution License (CC BY). The use, distribution or reproduction in other forums is permitted, provided the original author(s) and the copyright owner(s) are credited and that the original publication in this journal is cited, in accordance with accepted academic practice. No use, distribution or reproduction is permitted which does not comply with these terms. 